\title{
Prediction of fiber breakage and matrix cracking in polymeric composites under low-cycle fatigue regimes by fuzzy and wavelet clustering of acoustic emission signals
}

\author{
Sattar Mohammadi Esfarjani' ${ }^{1}$, Mohammad Azadi ${ }^{1 *}$, Mohsen Alizadeh², Hassan Sayar1
}

${ }^{1}$ Faculty of Mechanical Engineering, Semnan University, Semnan, Iran

${ }^{2}$ Faculty of Aerospace Engineering, Semnan University, Semnan, Iran

*Corresponding author, Tel.: +98-910-210-7280; Fax: +98-23-33321005

E-mail address: m_azadi@semnan.ac.ir

\begin{abstract}
One of methods for detecting cracks and estimating their growth in materials such as composites is the acoustic emission technique. The detection of damages, cracks and their growth in industrial composite structures, under static and dynamic loads, has a significant importance, in order to prevent any damages and increase the reliability. Therefore, achieving required technical knowledge in this field, can be helpful in repairing and the maintenance of the part in industries. The prediction of the damage in polymeric composites under static loads has been already investigated by researchers; however, under cyclic loadings, researches about this behavior are still rare. In this study, by acoustic emission sensors and analyzing experimental data, the damage, including matrix cracking, the fiber breakage and other damages (debonding, fiber pull-out and delamination) during dynamic loading was investigated. At the first stage, standard specimens were made by the pure resin epoxy and the pure carbon fiber, subjected to monotonic tensile loading and then, the frequency of the failure was extracted. Then, composite specimens were loaded in the low-cycle fatigue regime. Mechanical test results and acoustic emission data were analyzed by fuzzy C-Means and wavelet transform methods and then compared to each other to find the percentage of failures in first, mid- and last cycles by the differentiation of failure types. Results clearly indicated that the acoustic emission approach is useful and an effective tool for identifying and detecting damages in polymeric composites.
\end{abstract}

Keywords: Polymeric composite, Acoustic emission, Cyclic loading, Damage prediction, Lowcycle fatigue 


\section{Introduction}

Today, for the engineering industry, the demand for materials that are highly efficient is considered important and the need for advanced materials and the production processes is felt. Perhaps the most important requirements are the use of high-performance materials, low weight and relatively low price. Among these materials are composites that are widely used in the industry. Various defects occur in composite structures that require constant monitoring and the prevention of any damage. Damage to composites manifests itself in the form of the delamination, matrix cracking, the fiber breakage, debonding, and other damages. Due to the small size of the primary defects and the impossibility of the visual inspection, nondestructive tests (NDT) are used to detect and identify these defects [1-5]. NDT methods such as; radiography, ultrasonic testing, and penetrant testing are used traditionally for identifying defects, each one having advantages and disadvantages, making it more or less appropriate for a given application [6-10].

The dumbbell (dog-bone) shape is assessed to see whether it performs better under fatigue loading conditions, primarily meaning that damage does not occur in the tabbed section studied by Baere et al. [11]. They showed that the dumbbell shape is preferable to rectangular since the failure never occurred under or near the tabbed section, and fatigue life is highly underestimated when using the rectangular. Brunbauer et al. [12] investigated the effect of the fiber volume fraction on the fatigue behavior and damage mechanisms of carbon/epoxy laminates. The epoxy resin and unidirectional carbon/epoxy specimens with two different fiber volume fractions were tested under quasi-static tensile and tension-tension fatigue loads at angles of $0^{\circ}, 45^{\circ}$ and $90^{\circ}$. Fracture surfaces were studied with the scanning electron microscopy. The results of their research showed that the stiffness and the strength increased with increasing the fiber volume factor and the damage behavior of out-of-range samples changed with increasing the fiber volume and the load height of the applied cycle. In addition, in cross-fatigue tests with higher fiber direction, the models indicated more similar behavior with different volume fractions of fibers. The higher the applied load in fatigue tests transverse to the fiber direction, the more similar behave specimens with different fiber volume fractions [12].

The sensitivity analysis for effects of the displacement amplitude and the loading frequency on the low-cycle fatigue lifetime in carbon/epoxy laminated composites was investigated by Azadi et al. [13]. Experimental results illustrated that by increasing the displacement amplitude, the low-cycle fatigue lifetime decreased, as expected. In addition, when the loading frequency was enhanced, the low-cycle fatigue lifetime of composites decreased. Besides, the 
maximum stress had a reverse behavior, compared to the fatigue lifetime. The sensitivity analysis depicted that the displacement amplitude was sensitive on both the fatigue lifetime and the maximum stress. The loading frequency was sensitive to the maximum stress and was not sensitive to the fatigue lifetime [13].

Asokan et al. [14] studied acoustic emission monitoring of repaired composite laminates. Tensile specimens were fabricated under ASTM D3039 using double-sided glass/epoxy fibers and were impacted at 1.89 Joules. Then, the damaged region was repaired using different methods. Next, the impacted and differently repaired samples were subjected to tensile loading to failure, monitored using acoustic emission to evaluate the quality of repairing, obtained in particular distinguishing between the different failure modes, namely; matrix cracking, the delamination and the fiber breakage. The proposed methods could be used to create an automated method for evaluating composite structures in the future [14].

The delamination is a typical damage mode for laminated composites. Michalcova and Kadlec [15] studied crack growth monitoring in a climatic chamber on double-cantilever beam (DCB) specimens using optical devices and acoustic emission techniques. A relationship between cumulative acoustic emission energy and crack growth in a plain-weave carbon fiber-reinforced epoxy was investigated under constant displacement rate loading at $+80{ }^{\circ} \mathrm{C}$ and $-55^{\circ} \mathrm{C}$. Their results showed that crack growth curves had an average error of $3.49 \%$ with the acoustic emission [15].

The damage identification and the evaluation in cross ply laminates using acoustic emission and ultrasonics was studied by Aggelis et al. [16]. They concluded that the study of ultrasonic and the acoustic emission signals components could be a way to monitor composite structures.

$\mathrm{Ni}$ and Iwamoto [17] found the wavelet transform of acoustic emission signals in the failure of model composites. These illustrated that both processing methods of acoustic emission signals, the fast-Fourier transform and the wavelet transform, were powerful for identifying the micro damage modes and for elucidating the micro fracture mechanisms in composite materials [17]. A procedure for the investigation of the local damage in composite materials based on the analysis of the signals of the acoustic emission was presented by Marec et al. [18]. One of the problems with sound propagation signals was the extraction of the most critical failure mechanisms. The methods used by them for clustering included; the fuzzy method and the principal component analysis [18]. Identification effects of hybrid fibers in composite properties and acoustic emission parameters by Fuzzy C-Means were investigated by Nikmehr and Khamedi [19]. One of the main problems for the damage mechanisms 
identification by the acoustic emission method was discrimination of events due to different types of the damage, which occurred during loading of the composite material. The fuzzy CMeans clustering algorithm was a tool, which was used in this paper to separate acoustic events. The results demonstrated that the method of clustering provided a better correlation between the acoustic signals, damage mechanisms and also the time of these mechanisms. For analyzing the acoustic emission signals, some of the descriptors like the amplitude, the duration, the count, the acoustic energy and the rise time were used to identify the micro mechanisms of the failure. In the first steps of the hybrid composite loading, it was noisier than the last steps and it showed the progressive damage mechanisms [19].

Williams and Reifsnider [20] investigated the acoustic emission during fatigue loading of composite specimens. They found a good correlation between the percentage of the damage and its progression and the results of the acoustic emission. The acoustic emission energy as a fatigue damage parameter for carbon fiber reinforced polymer composites (CFRP) was studied by Bourchak et al. [21]. Their results showed that the composite damage occurred at about $27 \%$ of the final tensile strength and $0.3 \%$ of the final strain for the composite with $90^{\circ}$ layers. Loutas and Kostopoulos [22] studied woven carbon/carbon (C/C) composites subjected to repeated tensile loading. They used the acoustic emission during loading to monitor the status of the test sample. The threshold chosen by them was $40 \mathrm{~dB}$ [22].

Alizadeh et al. [23] studied health monitoring for composites under low-cycle cyclic loading, considering effects of the acoustic emission sensor type. Obtained results indicated that by increasing the number of cycles and approaching the final lifetime of the sample, the cumulative energy of signals increased. The fracture surface of specimens was analyzed using the scanning electron microscopy. As a consequent and a general conclusion, based on obtained results, it could be claimed that both wide-band and mid-band acoustic emission sensors could be effectively utilized for detecting the defects in composite structures [23]. The investigation of the displacement amplitude effect on failure mechanisms in open-hole laminated composites under low-cycle fatigue loading was studied by Alizadeh et al. [24], using the acoustic emission. First, the standard specimen was examined and elastic waves due to failures in the specimen were detected by acoustic emission wide-band sensors. Two methods have been utilized to detect the failure percent, including; pocket wavelet transform and fuzzy clustering approaches. Results from these methods were compared to microstructure images by the scanning electron microscopy. Obtained results in this research indicated the appropriate efficiency of the acoustic emission approach to detect the type of failures and their percent in laminate composites [24]. 
In this study, according to the reviewed sources, a perforated composite sample of carbon fibers and the epoxy resin in two directions and low-cycle fatigue loading were selected for testing. The wavelet transform method and fuzzy clustering for acoustic emission data analysis was used. Moreover, due to the fact that less research has been done in the field of monitoring composite structures with acoustic emission under low-cycle fatigue loads; therefore, this type of loading was selected for carbon fiber composite samples. The results were tested and analyzed. The type of loading and dimensions of the sample were completely in accordance with the standard [25]. The conditions of data collection and the expression of results in different cycles could be considered as a part of the innovation of this research.

\section{Materials and Tests}

In this study, composite specimens were manufactured of single-sided carbon fiber manufactured by the Sika Company (Sika Wrap-230 C) with a specific gravity of $230 \mathrm{gr} / \mathrm{m}^{2}$ and the epoxy resin manufactured by the Sika called CR-80. The CH-80-2 hardener was used to harden the resin, which was combined with the resin in a weight ratio of $30 \%$. The thickness of each layer of single-sided fabric was equal to $0.13 \mathrm{~mm}$, which after making the samples and combining with the resin, the thickness of each layer was approximately 0.22 $\mathrm{mm}$. After layering, in order to improve the quality of the manufactured samples and to control the volume percentage of the resin and fibers, as well as to control the final thickness, the layers were pressed very carefully by two polished steel plates and baked at room temperature. The produced composite samples plates were removed from the mold after 24 hours and placed in the room temperature, 20 to $25^{\circ} \mathrm{C}$, for one week before cutting. Then, the composite sheet was made with the dimension of $250 \times 350 \mathrm{~mm}$ and the thickness of $3.2 \mathrm{~mm}$, in the $\left[0_{3} / 90_{2} / 0_{2}\right]_{s}$ layout. Then, standard specimens were cut from this sheet according to ASTM D5766 [26] using the water-jet approach. Finally, a hole with a diameter of $6 \mathrm{~mm}$ was drilled in the center of the samples. Using the water-jet during cutting operations minimized damages such as the delamination to near zero.

To investigate the damages in the samples by the acoustic emission approach, the characteristics of the acoustic emission signals related to each of the damages must first be determined. To this purpose, samples of the pure resin and pure fibers were made. To make pure resin samples, after hardening was added to the resin, they were poured into the mold and removed from the mold after one week. To make pure fiber samples, carbon fiber fabric with a width of $20 \mathrm{~mm}$ and a length of $150 \mathrm{~mm}$ was cut and glued to aluminum plates. 
To obtain the acoustic emission signals related to the resin and fiber failures, first the pure resin and pure fiber tensile tests were performed at constant rates of 2, 5, 10 and 20 ( $\mathrm{mm} / \mathrm{min})$. For all samples, two sensors were connected to the samples to record the acoustic emission signals. For pure fiber samples, the sensors were attached to aluminum tubes and all samples were subjected to quasi-static loading. The signals were amplified with a factor of 40 $\mathrm{dB}$ by two pre-amplifiers and the appropriate threshold was set at $30 \mathrm{~dB}$. Three samples were loaded for the reproducibility at each rate. According to ASTM D5766, the layers must have at least two different angles in manufacturing. Moreover, the sample length should be in the range of 200 to $300(\mathrm{~mm})$ and the sample width should be $36(\mathrm{~mm})$. The hole should also be in the center of the specimen with a width to diameter ratio of 6.0 [25].

For repetitive tensile loading, it was first necessary to extract the maximum deformation of the specimens during damage. Therefore, the samples were loaded at a lower range. To this purpose, a sample was first subjected to tensile loading and the maximum amount of the deformation during damage was obtained. The loading case of the samples was in the form of the controlled displacement. It was done in two steps. In the first stage, the samples were subjected to the constant displacement and different frequencies. In the next stage, the samples were loaded with the constant rate and different displacements. The threshold of acoustic emission signals was set at $37 \mathrm{~dB}$ by using trial and error methods. In these tests, the acoustic emission signals were recorded by two sensors, each was located $2 \mathrm{~cm}$ from the center of the hole. Acoustic emission signals were amplified $40 \mathrm{~dB}$ by two 2/4/6 preamplifiers. In order to calibrate the sensors, the pencil lead break (PLB) method was utilized, according to the ASTM-E976 standard [26, 27].

\section{Analysis Methods}

In this research, the fast Fourier transform (FFT), the wavelet packet transforms, and fuzzy clustering methods were used to investigate the condition of structures by the acoustic emission signal processing and to determine the structural health monitoring (SHM) or the damage detection.

\subsection{Fast Fourier Transform (FFT)}

For the signal frequency analysis, one of the analysis methods is discrete Fourier transform (DFT), in which the fast Fourier transform is a method to reduce the amount of computations. Fourier transforms transmit the wave from the temporal space to the frequency space. The 
DFT can be used in functions that are sampled in the same time space and the time interval $[28,29]$.

If $g_{b}$ is the values of the samples and $N$ is the number of these samples and $b$ is their number, which varies from 0 to $N-1, g_{b}$ can be written as a series as Relation (1) [29].

$$
g_{b}=\sum_{n=0}^{N-1} c_{n} e^{\frac{2 \pi i b n}{N}}
$$

Equation (2) specifies the coefficients, $c_{n}$.

$$
c_{n}=\frac{1}{N} \sum_{n=0}^{N-1} g_{b} e^{\frac{-2 \pi i b n}{N}}
$$

By comparing the relations of the ordinary Fourier transform with Relation (3), the DFT $g_{b}$ is defined as Relation (4).

$$
\begin{aligned}
& h_{a}=\operatorname{DFT}\left(g_{b}\right)=\sum_{n=0}^{N-1} g_{b} e^{\frac{-2 \pi i b n}{N}} ; 0 \leq a<N \\
& h_{a}=\sum_{n=0}^{N-1} g_{b} W_{N}^{a b} ; W_{N}=e^{\frac{-2 \pi i}{N}}
\end{aligned}
$$

According to Equation (5), the calculations for the number of samples are in the order of $N^{2}$. In this case, $N$ is a power of two, and one of the FFT methods can be used to reduce the computational value. Data can be divided into even and odd categories at each stage. Instead of calculating for the whole data, binary Fourier transforms can be recursively combined to reach the original Fourier transform. The $g_{b}$ data is divided into two pairs, $g_{e v}$ and $g_{o d d}$, and Relation (6) is rewritten [29].

$$
\begin{aligned}
& h_{a}=\sum_{b=0}^{N / 2-1} g_{2 b} W_{N}^{a b}+\sum_{b=0}^{N / 2-1} g_{2 b+1} W_{N}^{a(2 b+1)} \\
& h_{a}=\sum_{b=0}^{N / 2-1} g_{2 b} W_{N / 2}^{a b}+W_{N}^{a} \sum_{b=0}^{N / 2-1} g_{2 b+1} W_{N / 2}^{a b}
\end{aligned}
$$

The first part of Equation (6) is the discrete Fourier transform of even elements and the second part is the discrete Fourier transform of odd elements multiplied by $W_{N}^{a}$.

$$
h_{a}=\operatorname{DFT}\left(g_{e v}\right)+W_{N}^{a}\left(g_{o d d}\right)
$$

By continuing to categorize data in pairs and using Relation (7), the computational order is reduced to $N \log _{2}^{N}[26]$. 


\subsection{Wavelet Transform}

A wavelet is a wave with a mean value of zero and a finite period. If the $\psi$ function with two conditions has a finite energy function and the integral of the function is in the range $(-\infty, \infty)$ equal to zero, a wavelet or mother wavelet is called as Relations (8) and (9) [24, 30, 31]:

$\int_{-\infty}^{+\infty}|\psi(t)|^{2} d t<\infty$

$\int_{-\infty}^{+\infty} \psi(t) d t=0$

Relations (10) and (11) show the discrete wavelet transform (DWT) and inverse it, respectively [18]:

$f(t)=c \sum \sum D W T(i, k) 2^{\frac{-i}{2}} \psi\left(2^{-i} t-k\right)$

$\operatorname{DWT}(i, k)=\int_{-\infty}^{+\infty} f(t) 2^{\frac{-i}{2}} \psi^{*}\left(2^{i} t-k\right) d t$

Where, $f(t)$ is the processed signal, $D W T(i, k)$ is the wavelet transform coefficient, $i$ is the decomposition level, $k$ is the transfer parameter and $\psi$ is the mother wavelet.

In this research, the wavelet packet transform (WPT) is used because the wavelet transform divides the signal into two parts, general and detailed, only in the first level. In the next levels, only generalities are decomposed, while in the wavelet transform, the packages of all components at all levels are decomposed into low-frequency segments, which are related to generalities, and high-frequency, which is related to details. This difference is shown in Figure 1, which has been used in previous research in recent years [32].

(a)

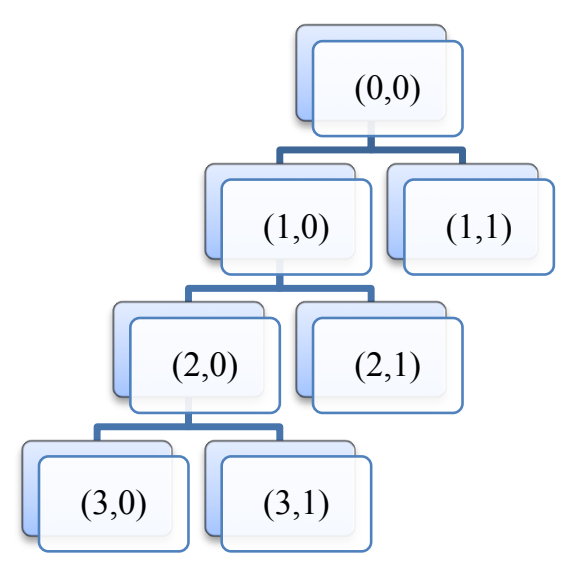


(b)

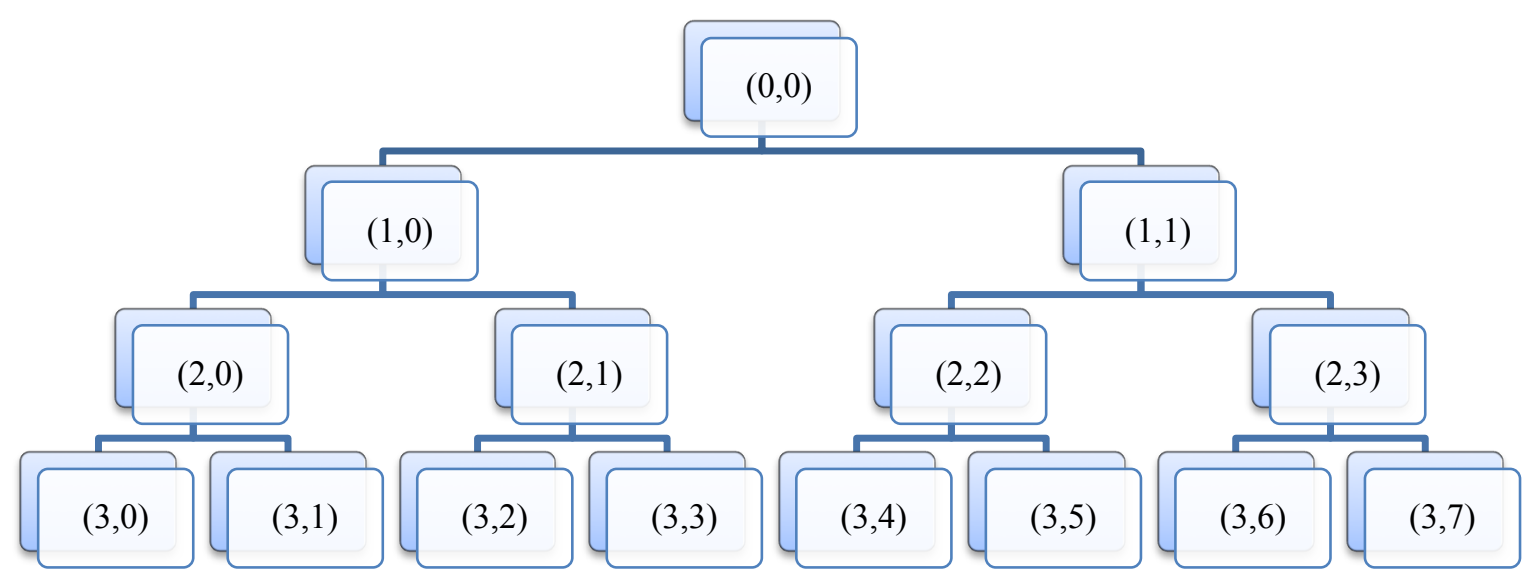

Figure 1: The wavelet transforms: (a) the discrete type and (b) the packet type [21]

As mentioned, in transforming a packet wavelet at each level, in addition to the analysis of generalities, the details are also decomposed into two levels of generalities and details.

The frequency range of generalities and details at each level is calculated with Relations (12) and (13) [33]:

$\left[0, \frac{1}{2} f_{s} 2^{-1}\right]$

$\left[\frac{1}{2} f_{s} 2^{-1}, \frac{1}{2} f_{s} 2^{-(i-1)}\right]$

Which $f_{s}$ is the vector data rate and the $2^{-1}$ number of components at the $i$ level. The components of the desired wavelet pack are decomposed into $\varphi$ at level $i$. The energy of the components is also defined as level $i$, which is expressed mathematically in Relation (14) [24, 34]:

$E_{i}^{j}(t)=\sum_{\tau=t_{0}}^{t}\left(f_{i}^{j}(\tau)\right)^{2}$

And the total signal energy from the relation (15) can be calculated [24, 34]:

$E_{\text {Total }}(t)=\sum E_{i}^{j}(t) \quad j=1, \ldots, 2^{i}$

The ratio of the energies of each component to the total energy of the signal determines the energy distribution in each of the decomposed components. The energy distribution indicated by $P_{i}^{j}(t)$ is shown in Relation (16) [24, 34]:

$P_{i}^{j}(t)=\frac{E_{i}^{j}(t)}{E_{\text {Total }}(t)} \quad j=1, \ldots, 2^{i}$ 


\subsection{Fuzzy Clustering Method}

The fuzzy clustering method refers to a clustering technique, in which each data belongs to a cluster and has a degree. This method is one of the advanced clustering methods introduced by Bezdak. A set of data including $n$ data to $c$ different clusters want to be clustered, $X=$ $\left\{X_{1}, X_{2}, \ldots, X_{n}\right\}$ and each data $x_{i}$ defined by $m$ characteristic. That's mean, $X=$ $\left\{X_{1}{ }^{1}, X_{2}{ }^{2}, \ldots, X_{n}{ }^{m}\right\}$ where $X_{i}$ is in the set $X$ ( $X$ is a next $m$ space). Since all $m$-properties have different units, we must normalize each property with a single-scale scale before clustering $[24,35]$.

The objective function method is used to cluster $n$ data into $c$ different clusters. The main purpose of this function is to bring the distance between data in a particular category and a point called the center point of that category to the lowest value and to create the maximum distance between the center points of each category relative to the other category $[24,36]$.

For a point like $x_{k}$, the function will be the value of the membership in the $k$ data and the $i$ cluster as a Relation (17) [36]:

$u_{i k}=u_{i k}\left(X_{k}\right) \in[0,1]$

It should be noted that for a particular point in all clusters the sum of all membership values will be equal to one and the cluster cannot be empty of any data or contain all data in the form of Relations (18) and (19) [36]:

$\sum_{i=1}^{c} u_{i k}=1$
$0<\sum_{i=1}^{c} u_{i k}<1$

The objective function used in fuzzy clustering will be in the form of Relations (20) and (21) [36]:

$$
\begin{aligned}
& J(u, v)=\sum_{k=1}^{n} \sum_{i=1}^{c}\left(u_{i k}\right)^{m}\left(d_{i k}\right)^{2} \\
& d_{i k}=d\left(x_{k}-v_{i}\right)=\left[\sum_{j=1}^{m}\left(x_{k j}-v_{i j}\right)^{2}\right]^{\frac{1}{2}}
\end{aligned}
$$

Where $d_{i k}$ is the distance between $x_{k}$ from the center $v_{i}$ and $u_{i k}$ is the $k$-value of the amine data membership in the $i$ cluster. Then, $m$ is the amount of weight that determines the fuzzy value of clustering. Moreover, $v_{i}$ in Relation (22) is the center of the $i$ cluster [24, 37].

$v_{i}=\frac{\sum_{k=1}^{n}\left(u_{i k}\right)^{\dot{m}} \cdot x_{k}}{\sum_{k=1}^{n}\left(u_{i k}\right)^{\dot{m}}}$ 
When using fuzzy clustering, first the number of clusters is determined for data with values between zero and one as $u$. Then, the matrix of the random membership function is selected. These values are assigned to each of the data. The values associated with the centers of the clusters are then determined, and the operation continues again until the Relation (23) is established.

||$u^{r+1}-u^{r}|| \leq \varepsilon$

Where, $r$ is the number of iterative steps and $\varepsilon$ is the error value that is calculated compared to the previous step and must be less than the specified value to stop the clustering process [38].

\section{Results}

\subsection{Pure Resin Tests}

\subsubsection{The effect of the loading rate}

The results of the force-displacement diagrams of the tensile test are shown in Figure 2. It shows that with increasing the loading rate, the maximum amount of the force increased and it was directly related to it. Moreover, there is no significant behavior or trend could be seen in the amount of the displacement corresponding to the maximum force, which was in an agreement with the results of other researchers [39-44]. Although Gilat et al. [45] showed that in E-862 and PR-520 resins, the strain rate had an effective change on the material behavior. The resin type in this research was CR-80.

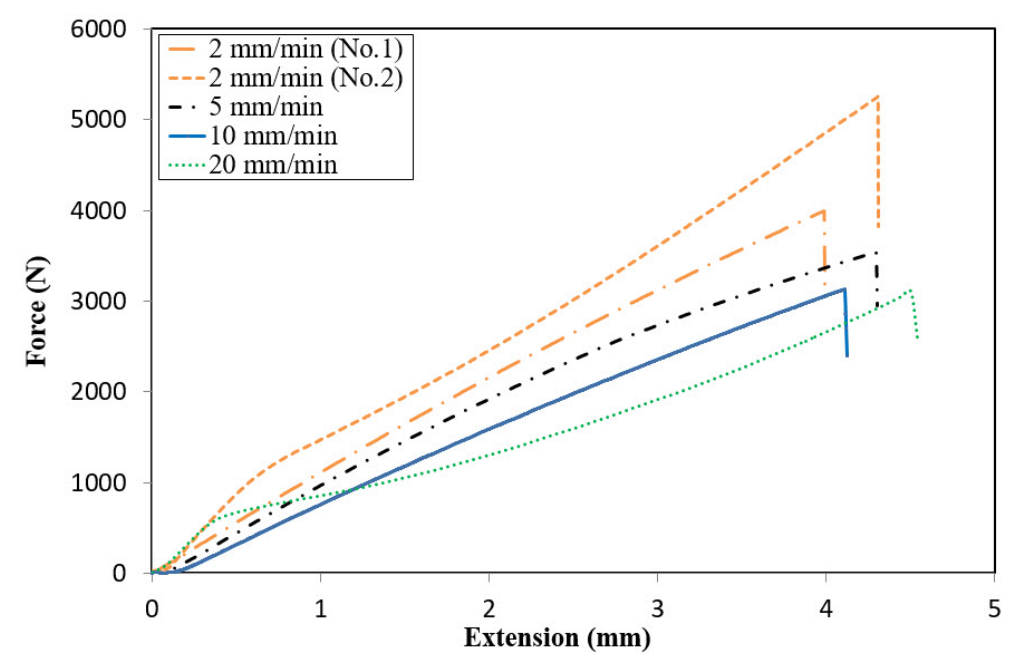

Figure 2: Force-displacement diagrams of the pure resin test 


\subsubsection{The dominant frequency of damages}

To analyze the frequency of data obtained from the acoustic emission signals related to the damage of the main component test, the acoustic data obtained from the pure resin tensile test were rapidly transformed from the time domain to the frequency range by the Fourier transform (FT) method. As a result, the dominant crack frequency of the resin was determined. Figures 3 and 4 are shown the waveform and the frequency range of the pure resin test, respectively. As shown in Figures 3 and 4, the maximum recorded frequency was $500 \mathrm{kHz}$. Due to data rate of $1 \mathrm{M} / \mathrm{s}$ and the fact that the frequency range was related to the matrix cracking damage of 250-100 kHz, which was consistent with the previous research. These results were matched with previous researches [46,47].

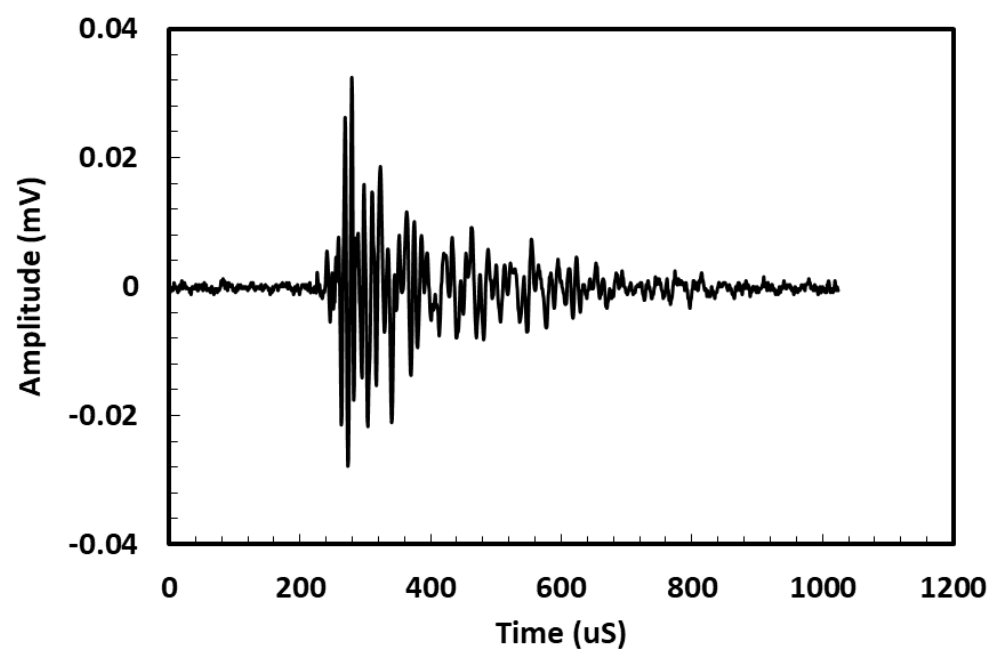

Figure 3: The waveform related to matrix cracking

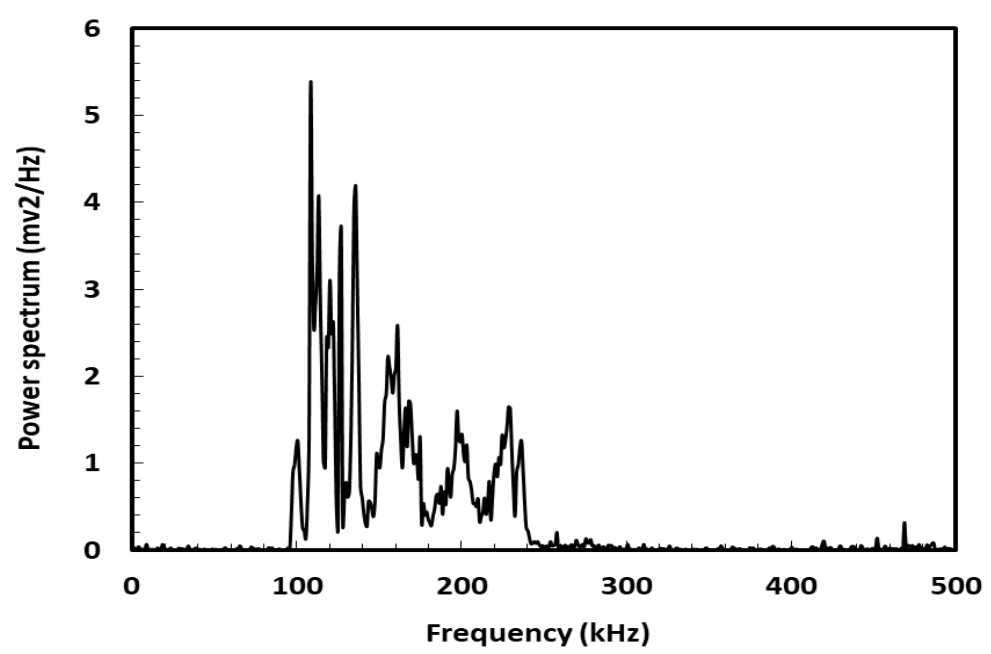

Figure 4: The frequency range related to matrix cracking 


\subsection{Pure Fiber Tests}

\subsubsection{The effect of the loading rate}

The results of the force-displacement diagrams of the tensile test are shown in Figure 5. Unlike the pure resin tensile test, the pure fiber tensile test indicated that as the loading rate increased, the maximum force decreased and this trend was inversely related to it. Moreover, there was no effective difference in the amount of the displacement corresponding to the maximum force, as in the pure resin test. In other words, no obvious trend could be found for the displacement at the fracture, by enhancing the loading rate. Therefore, there was a good match between these results and the results of another research [43].

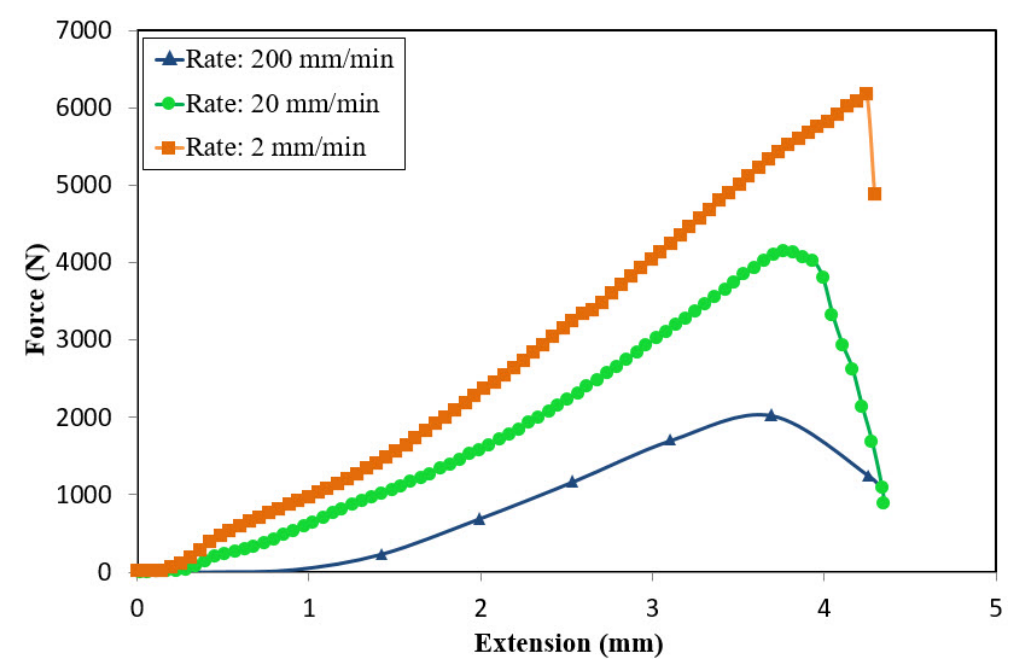

Figure 5: Force-displacement diagrams of the pure fiber test

\subsubsection{The dominant frequency of damages}

Like the pure resin test, data related to the acoustic emission signals were analyzed by the FFT method and the frequency range related to the damage of fibers of $420-500 \mathrm{kHz}$ was determined. The only remaining band in the frequency range, $450-250 \mathrm{kHz}$, was allocated to other damages (debonding, fiber pull-out and delamination), which there was in acceptable agreement with other results $[40,46,47]$. Figures 6 and 7 indicate the waveform and the frequency range for the pure fiber test, respectively. 


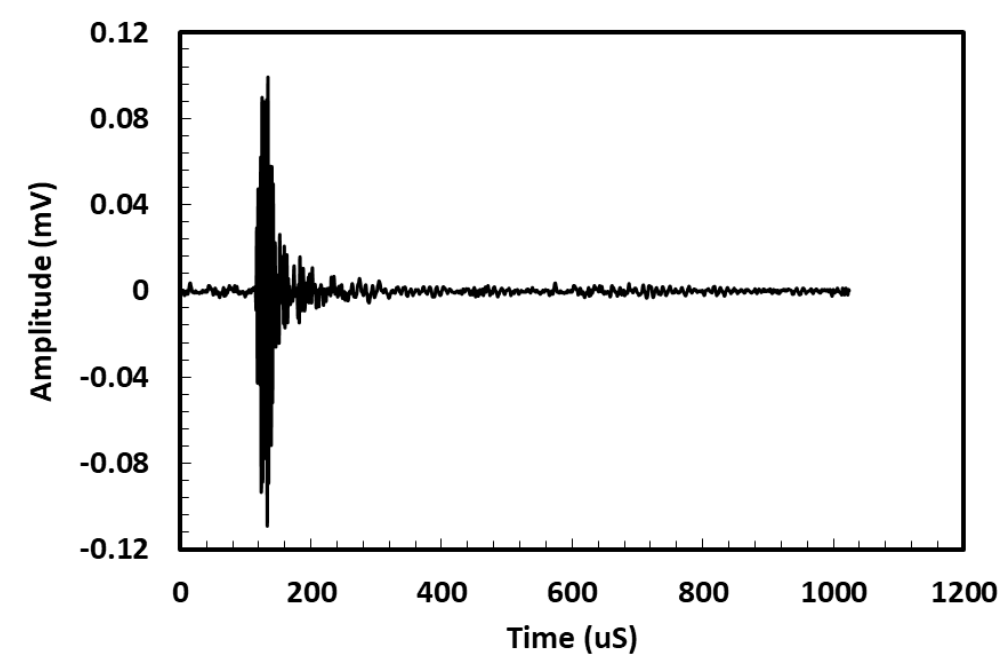

Figure 6: The waveform related to the fiber breakage

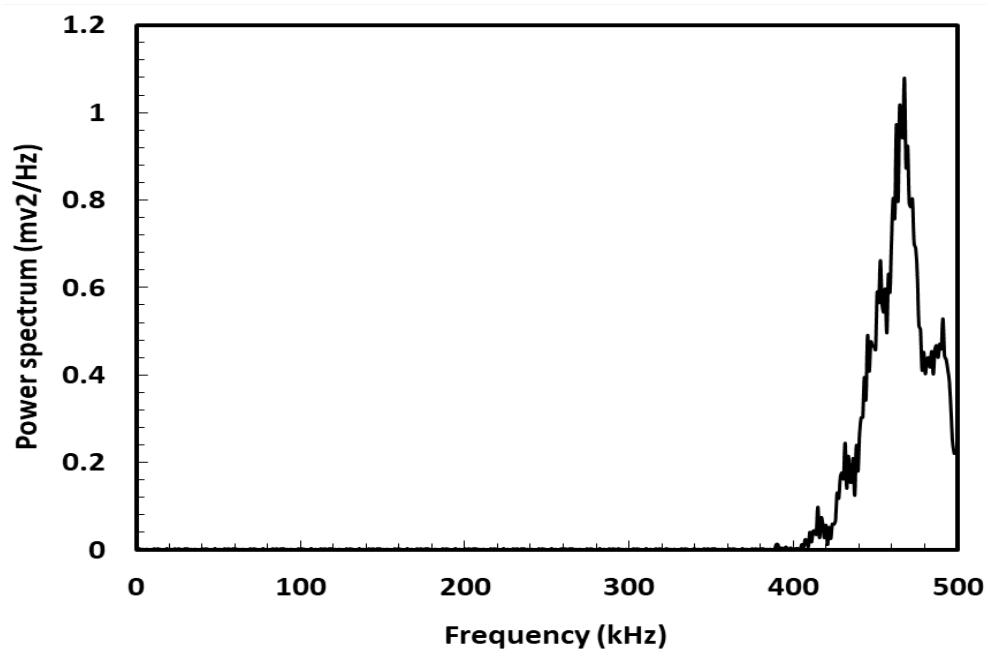

Figure 7: The frequency range related to the fiber breakage

\subsection{Fatigue Tests of Composite Samples}

Perforated composite specimens were subjected to two different types of loading. In the first series, loads with a constant amplitude and different frequencies were applied. In the second series, loads with a constant frequency (or rate) and different amplitudes were applied. In the following, the lifetime of the samples in each type of loading was examined. The effect of the frequency and the amplitude was also discussed.

\subsubsection{The effect of the loading rate on the lifetime}

Perforated composite samples were each loaded separately with different frequencies, the results of which can be seen in Table 1. In these tests, the constant amplitude of $7.0 \mathrm{~mm}$ was considered. As can be seen from the results, with increasing the frequency, the lifetime decreased and the amount of the maximum stress increased. Figure 8 shows the maximum 
stress-lifetime diagram of the samples, which is mentioned in Table 1. Figure 9 indicates the behavior of the material under the fatigue load. The closer the part was to its final lifetime and the longer the loading cycle, the amount of the maximum stress decreased. Figure 9 can predict the lifetime of the part under the fatigue load with the constant amplitude and the variable frequency. In a fatigue load with a constant amplitude, with increasing the loading rate, the lifetime of the sample shortened. These results were matched with the previous research [48].

Table 1: The results of fatigue tests under the constant amplitude and the variable frequency

\begin{tabular}{|c|c|c|c|c|c|}
\hline $\begin{array}{c}\text { Sample } \\
\text { number }\end{array}$ & $\begin{array}{c}\text { Loading frequency } \\
(\mathrm{mm} / \mathrm{min})\end{array}$ & $\begin{array}{c}\text { Amplitude } \\
(\mathrm{mm})\end{array}$ & $\begin{array}{c}\text { Max } \\
\text { tension } \\
(\mathrm{MPa})\end{array}$ & $\begin{array}{c}\text { Min } \\
\text { tension } \\
(\mathrm{MPa})\end{array}$ & $\begin{array}{c}\text { Lifetime } \\
\text { (cycle) }\end{array}$ \\
\hline 1 & 25 & 7.0 & 406 & 2.0 & 42 \\
\hline 2 & 50 & 7.0 & 425 & 1.0 & 17 \\
\hline 3 & 100 & 7.0 & 452 & 2.0 & 14 \\
\hline 4 & 200 & 7.0 & 722 & 2.0 & 3 \\
\hline
\end{tabular}

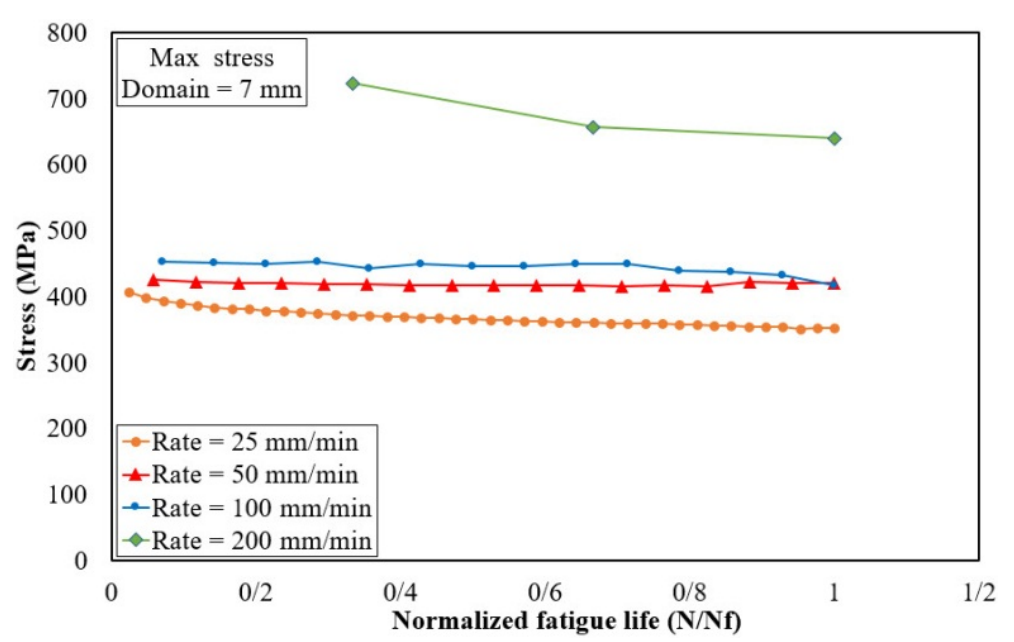

Figure 8: The diagram of the maximum stress-fatigue lifetime with the constant amplitude 


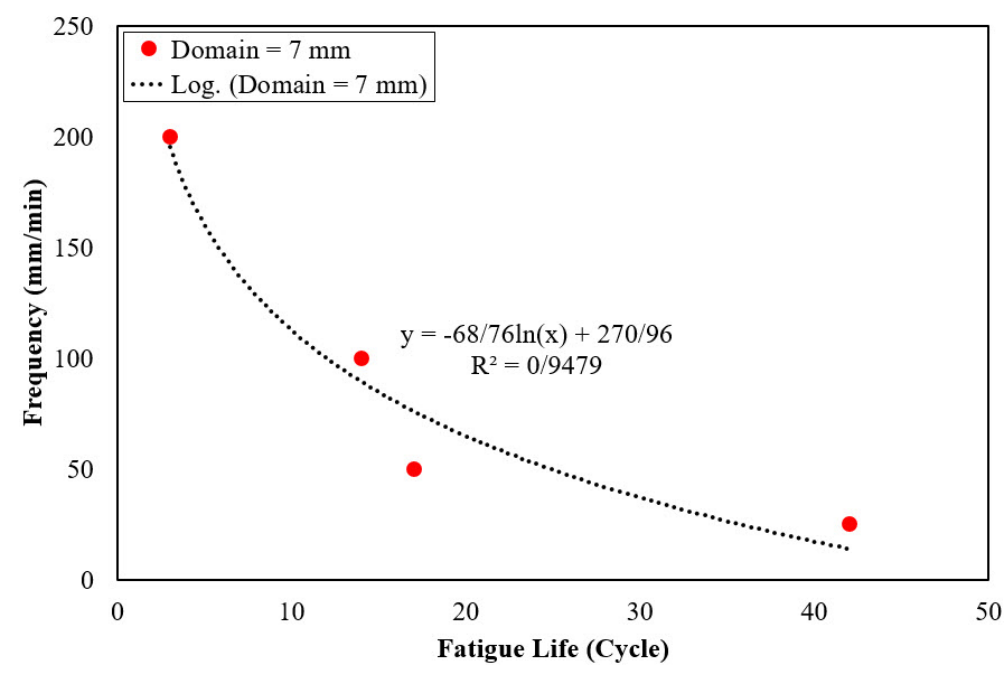

Figure 9: The diagram of the frequency-fatigue lifetime with the constant amplitude

\subsubsection{The effect of the loading amplitude on lifetime}

Table 2 shows the test results of samples 4 to 7 . In these tests, a constant frequency of 200 $\mathrm{mm} / \mathrm{min}$ was considered. As the results showed, when the loading frequency was constant and the amplitude increased, the lifetime of the samples decreased and the maximum stress increased. Figure 10 indicates the maximum stress-lifetime diagram of the samples, which is mentioned in Table 2. Figure 11 illustrates the occurrence of the softening phenomenon of the material. With increasing the number of load cycles and the closer the sample was to its final lifetime, the maximum stress decreased. From Figure 11, the fatigue lifetime could be predicted by changing the amplitude, which was matched with the previous research [48].

Table 2: The results of fatigue tests with the constant frequency and the variable amplitude

\begin{tabular}{|c|c|c|c|c|c|}
\hline $\begin{array}{c}\text { Sample } \\
\text { number }\end{array}$ & $\begin{array}{c}\text { Loading frequency } \\
(\mathrm{mm} / \mathrm{min})\end{array}$ & $\begin{array}{c}\text { Amplitude } \\
(\mathrm{mm})\end{array}$ & $\begin{array}{c}\text { Max } \\
\text { tension } \\
(\mathrm{MPa})\end{array}$ & $\begin{array}{c}\text { Min } \\
\text { tension } \\
(\mathrm{MPa})\end{array}$ & $\begin{array}{c}\text { Lifetime } \\
\text { (cycle) }\end{array}$ \\
\hline 4 & 200 & 7.0 & 722 & 2.0 & 3 \\
\hline 5 & 200 & 6.5 & 656 & 1.0 & 19 \\
\hline 6 & 200 & 6.0 & 550 & 1.0 & 39 \\
\hline 7 & 200 & 5.5 & 451 & 1.5 & 57 \\
\hline
\end{tabular}




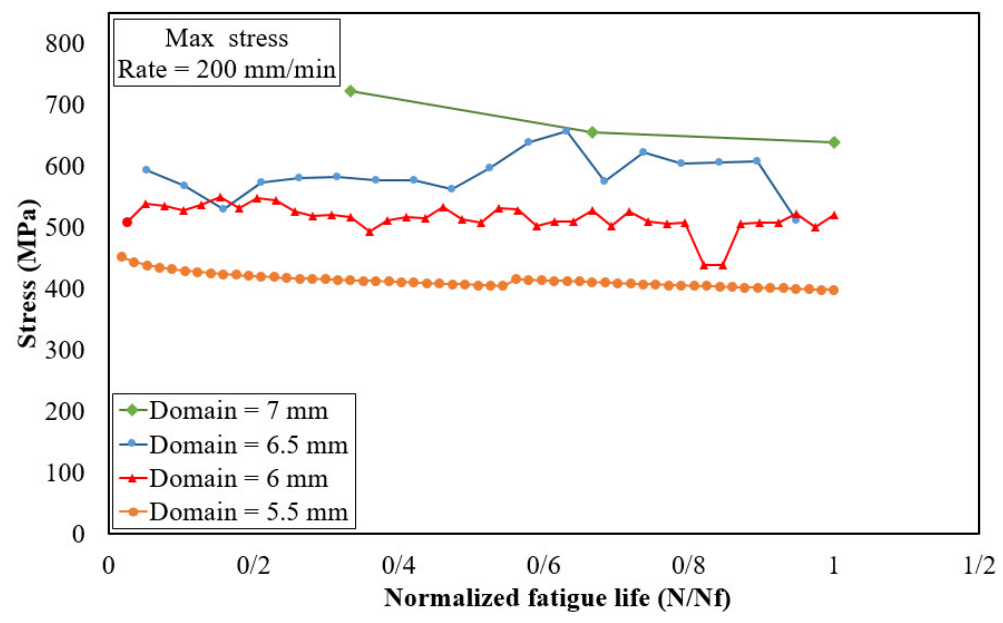

Figure 10: The diagram of the maximum stress-fatigue lifetime with the constant frequency

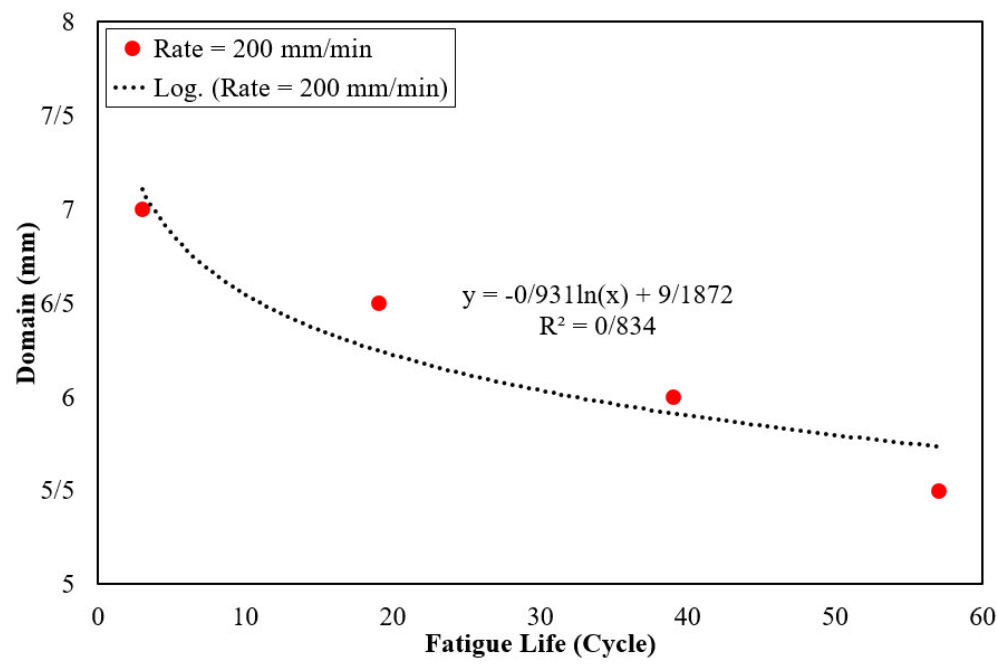

Figure 11: The diagram of the amplitude-lifetime with the constant frequency

\subsection{Damage Mechanisms by Acoustic Emission Signals}

\subsubsection{The classification of damage mechanisms by the wavelet method}

After recording the acoustic emission signals data by the sensors, the wavelet packet conversion was used to determine the percentage of damage mechanisms in each test. To convert the wavelet packet, the acoustic emission signals were broken down into three levels and into eight components using a code written in the MATLAB software. For fatigue tests, data related to first, mid- and last cycles were also analyzed by the wavelet method. All related figures are depicted in the appendix, at the end of the article.

\subsubsection{The classification of damage mechanisms by the wavelet method for the constant amplitude}

The results of the analysis of the acoustic emission signals for the constant amplitude and the variable frequency fatigue tests were calculated by the wavelet method for the first, mid- and 
last cycles of each test. The percentage of each type of damage mechanisms such as the fiber breakage, matrix cracking and other damages in each cycle was expressed. Then, the total percentage of each damage mechanism was calculated according to the results obtained for these three cycles. Finally, an overall average was taken from the average of the damages. It represents the percentage of damages in a total of three cycles for four samples (Table 3). As can be seen in the results of Table 3, with increasing the loading frequency, the average percentage of the fiber damage increased, and the matrix cracking decreased and other damages were found. These results were matched with the previous research $[49,50]$. Such results were also represented in the literature [51], only for the fiber breakage failure mechanism.

Table 3: Damage mechanisms of constant amplitude fatigue tests by the wavelet method

\begin{tabular}{|c|c|c|c|c|c|c|c|c|c|c|c|c|c|c|}
\hline \multirow[b]{2}{*}{ 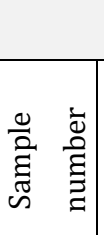 } & \multirow[b]{2}{*}{$\begin{array}{l}\text { Amplitude } \\
\text { (mm) }\end{array}$} & \multirow[b]{2}{*}{$\begin{array}{l}\text { Loading } \\
\text { frequency } \\
(\mathrm{mm} / \mathrm{min})\end{array}$} & \multicolumn{4}{|c|}{ Fiber breakage (\%) } & \multicolumn{4}{|c|}{ Other damages (\%) } & \multicolumn{4}{|c|}{ Matrix cracking (\%) } \\
\hline & & & 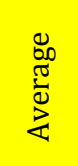 & 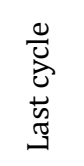 & 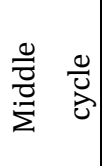 & 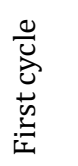 & $\begin{array}{l}8 \\
\frac{\pi}{0} \\
\stackrel{0}{0}\end{array}$ & 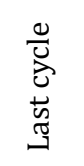 & $\begin{array}{ll}\frac{0}{\bar{*}} & \frac{0}{0} \\
\stackrel{0}{\Sigma} & 0\end{array}$ & 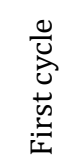 & 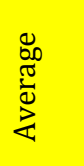 & 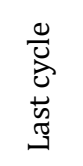 & 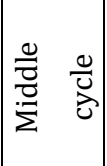 & 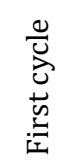 \\
\hline 1 & 7.0 & 25 & 17.8 & 15.8 & 25.5 & 12.1 & 49.0 & 56.5 & 37.2 & 53.1 & 32.3 & 27.7 & 37.3 & 34.8 \\
\hline 2 & 7.0 & 50 & 18.5 & 22.1 & 18.8 & 14.5 & 50.3 & 47.9 & 55.5 & 47.5 & 31.3 & 30.0 & 25.7 & 38.0 \\
\hline 3 & 7.0 & 100 & 19.0 & 22.7 & 15.2 & 19.1 & 50.6 & 46.9 & 55.7 & 49.1 & 30.4 & 30.4 & 30.1 & 30.8 \\
\hline 4 & 7.0 & 200 & 19.1 & 20.9 & 18.7 & 17.7 & 50.9 & 53.7 & 54.9 & 44.1 & 30.0 & 25.4 & 26.4 & 38.2 \\
\hline \multicolumn{3}{|c|}{ Final average } & \multicolumn{4}{|c|}{18.6} & \multicolumn{4}{|c|}{$\frac{1}{50.2}$} & \multicolumn{4}{|c|}{31.2} \\
\hline
\end{tabular}

\subsubsection{The classification of damage mechanisms by the wavelet method for the constant rate}

In this section, mechanisms of the damage with the wavelet method for fatigue loading with the constant frequency and the variable amplitude were investigated. The results were given for the first, mid- and last cycles. Then, the average percentage of each type of damage is calculated for each sample. Finally, an overall average is taken from the average of the damages. It represents the percentage of failures in a total of three cycles for four samples (Table 4). As can be seen in the results of Table 4, with increasing the loading amplitude, the average percentage of the fiber breakage decreased, and the matrix cracking and other damages increased. These results were in good agreement with previous researches $[18,44,50]$. 
Table 4: Damage mechanisms of constant rate fatigue tests by the wavelet method

\begin{tabular}{|c|c|c|c|c|c|c|c|c|c|c|c|c|c|c|}
\hline & & & \multicolumn{4}{|c|}{ Fiber breakage (\%) } & \multicolumn{4}{|c|}{ Other damages (\%) } & \multicolumn{4}{|c|}{ Matrix cracking (\%) } \\
\hline 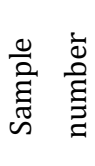 & $\begin{array}{l}\text { Amplitude } \\
\text { (mm) }\end{array}$ & $\begin{array}{l}\text { Loading } \\
\text { frequency } \\
(\mathrm{mm} / \mathrm{min})\end{array}$ & $\begin{array}{l}0 \\
\infty \\
\frac{\pi}{0} \\
8 \\
2\end{array}$ & 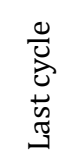 & 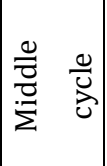 & 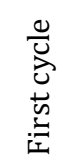 & 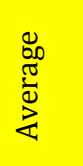 & 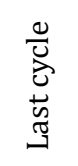 & 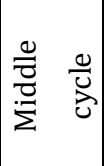 & 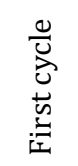 & $\begin{array}{l}\mathscr{8} \\
\frac{\pi}{0} \\
\frac{\pi}{2}\end{array}$ & 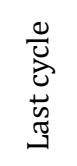 & 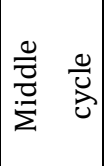 & 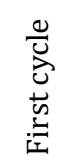 \\
\hline 4 & 7.0 & 200 & 19.1 & 20.9 & 18.7 & 17.7 & 50.9 & 53.7 & 54.9 & 44.1 & 30.0 & 25.4 & 26.4 & 38.2 \\
\hline 5 & 6.5 & 200 & 27.0 & 20.8 & 29.4 & 31.0 & 43.1 & 47.2 & 39.8 & 41.9 & 29.9 & 32.0 & 30.8 & 27.1 \\
\hline 6 & 6.0 & 200 & 28.3 & 29.7 & 29.6 & 25.8 & 42.3 & 39.7 & 40.4 & 47.0 & 29.4 & 30.6 & 30.0 & 27.2 \\
\hline 7 & 5.5 & 200 & 29.6 & 33.7 & 32.3 & 22.7 & 41.4 & 38.4 & 40.8 & 45.2 & 29.0 & 27.9 & 26.9 & 32.1 \\
\hline \multicolumn{3}{|c|}{ Final average } & \multicolumn{4}{|c|}{26.0} & \multicolumn{4}{|c|}{44.4} & \multicolumn{4}{|c|}{29.6} \\
\hline
\end{tabular}

\subsubsection{The comparison of the average results of the wavelet method for the constant} amplitude and the constant rate

In Table 5, the percentage of matrix cracking, the fiber breakage and other damages (debonding, fiber pull-out and delamination) are compared in two types of the constant amplitude fatigue tests and the constant frequency fatigue tests. The results showed that while the fiber fracture did not change much in the two types of loading; however, in the constant amplitude fatigue load, the percentage of other damages (debonding, fiber pull-out and delamination) was higher. Moreover, the fiber fracture percentage was less than the constant frequency fatigue loading, when the amplitude was variable. Therefore, changes in the frequency and the amplitude do not have much effect on matrix cracking. The highest percentage difference was related to the fiber breakage with about $7.4 \%$ and the lowest difference was related to matrix cracking with about $1.6 \%$. The difference between other damages in the two types of fatigue loads was 5.8\%. These results were in a good agreement with the previous research [18].

Table 5: The comparison of the average results of the wavelet method in the constant amplitude and the constant rate

\begin{tabular}{|c|c|c|c|c|c|}
\hline $\begin{array}{c}\text { Damage } \\
\text { loading type }\end{array}$ & $\begin{array}{c}\text { Loading } \\
\text { frequency } \\
\text { (mm/min) }\end{array}$ & $\begin{array}{c}\text { Amplitude } \\
(\mathrm{mm})\end{array}$ & $\begin{array}{c}\text { Matrix } \\
\text { cracking (\%) }\end{array}$ & $\begin{array}{c}\text { Other } \\
\text { damages } \\
(\%)\end{array}$ & $\begin{array}{c}\text { Fiber } \\
\text { breakage } \\
(\%)\end{array}$ \\
\hline $\begin{array}{c}\text { Constant } \\
\text { amplitude }\end{array}$ & from 25 to 200 & 7.0 & 31.2 & 50.2 & 18.6 \\
\hline Constant rate & 200 & $\begin{array}{c}\text { from 5.5 to } \\
7.0\end{array}$ & 29.6 & 44.4 & 26.0 \\
\hline
\end{tabular}




\subsubsection{The classification of damage mechanisms by the fuzzy clustering method}

To analyze the acoustic emission signals by the fuzzy clustering method, six characteristics of the peak time, the multiplication, the energy, the amplitude, the average frequency and the maximum frequency were used. In order to select the most effective parameter of the acoustic characteristics and to reduce the volume of information, the principal component analysis (PSA) method was utilized. In this method, in addition to displaying the best part of acoustic emission data, the volume of information was reduced and the most effective features were selected. First, each signal that contained a 6-dimensional space was analyzed. With the help of this method, the covariance between data was calculated. Then, the Eigen-vectors were calculated. Next, the percentage of the variance for each of them was obtained. The two vectors with the highest percentage of the variance could transfer from $6 \mathrm{D}$ to $2 \mathrm{D}$ with the minimal data reduction.

After reducing the dimensions made by the main components, the data points were clustered by the fuzzy method. In this case, they were divided into three main mechanisms; the matrix cracking damage, the fiber breakage and other damages (debonding, fiber pull-out and delamination). In the fuzzy clustering method, first, the best center of each cluster was determined based on the lowest limit of the objective function and the iterative methods. Then, acoustic emission data that were close to each of these centers were considered as data of that class. As mentioned, data were divided into three different clusters and have their own characteristics, one of which is the frequency distribution. Each data before clustering had its own feature. One of these features was the maximum frequency. Therefore, it is possible to determine the damage mechanism of each cluster with the help of this feature related to data of each cluster. In order to determine which failure mechanism each cluster belongs to; data of each cluster was plotted based on the frequency distribution. The frequency distribution was the use of the maximum frequency associated with each data. According to the tests of the pure resin and pure fibers and their frequency range, it was possible to determine which failure mechanism belongs to each cluster.

After classifying and clustering data, the percentage of each of the failure mechanisms of the two types of fatigue loading related to the fuzzy clustering method was calculated. The classification of failure mechanisms by the fuzzy clustering method for fatigue loads with the constant amplitude for test data of samples 1 to 4 is mentioned in Table 6 . The results of Table 6 showed that under loading of the constant amplitude and the variable frequency, with increasing the loading frequency, the percentage of matrix cracking and other damages increased and the percentage of the fiber breakage decreased. The classification of damage 
mechanisms by the fuzzy clustering method for the constant frequency fatigue loading is given in Table 7 for test data of samples 4 to 7 . The results of Table 7 indicated that in fatigue loads with the constant frequency and the variable amplitude, with increasing the loading amplitude, the percentage of the fiber breakage and other damages increases and the percentage of matrix cracking decreased. Table 8 compared the fuzzy clustering results for the constant amplitude and the constant frequency fatigue loads. The results of Table 8 illustrated that the largest difference in the damage percentage in fatigue loads with the constant amplitude and the constant frequency belong to matrix cracking, which was about $12.5 \%$. The percentage difference of other damages was $6.6 \%$ and the percentage difference of the fiber damage was 5.9\%. Such results were also represented in the literature [51], which showed the highest frequency ranges would be achieved during the fiber breakage [44,50-52].

Table 6: Damage mechanisms by the fuzzy clustering method for fatigue tests with the constant amplitude

\begin{tabular}{|c|c|c|c|c|c|}
\hline $\begin{array}{c}\text { Sample } \\
\text { number }\end{array}$ & $\begin{array}{c}\text { Loading frequency } \\
(\mathrm{mm} / \mathrm{min})\end{array}$ & $\begin{array}{c}\text { Amplitude } \\
(\mathrm{mm})\end{array}$ & $\begin{array}{c}\text { Matrix } \\
\text { cracking (\%) }\end{array}$ & $\begin{array}{c}\text { Other } \\
\text { damages (\%) }\end{array}$ & $\begin{array}{c}\text { Fiber } \\
\text { breakage (\%) }\end{array}$ \\
\hline 1 & 25 & 7.0 & 19.1 & 58.1 & 22.8 \\
\hline 2 & 50 & 7.0 & 19.3 & 58.8 & 21.9 \\
\hline 3 & 100 & 7.0 & 19.6 & 59.1 & 21.3 \\
\hline 4 & 200 & 7.0 & 23.3 & 60.4 & 16.3 \\
\hline & Final average & 20.3 & 59.1 & 20.6 \\
\hline
\end{tabular}

Table 7: Damage mechanisms by the fuzzy clustering method for fatigue tests with the constant rate

\begin{tabular}{|c|c|c|c|c|c|}
\hline $\begin{array}{c}\text { Sample } \\
\text { number }\end{array}$ & $\begin{array}{c}\text { Loading frequency } \\
(\mathrm{mm} / \mathrm{min})\end{array}$ & $\begin{array}{c}\text { Amplitude } \\
(\mathrm{mm})\end{array}$ & $\begin{array}{c}\text { Matrix } \\
\text { cracking (\%) }\end{array}$ & $\begin{array}{c}\text { Other } \\
\text { damages (\%) }\end{array}$ & $\begin{array}{c}\text { Fiber } \\
\text { breakage (\%) }\end{array}$ \\
\hline 4 & 200 & 7.0 & 23.3 & 60.4 & 16.3 \\
\hline 5 & 200 & 6.5 & 31.3 & 53.5 & 15.2 \\
\hline 6 & 200 & 6.0 & 36.1 & 49.1 & 14.8 \\
\hline 7 & 200 & 5.5 & 40.4 & 46.9 & 12.7 \\
\hline & Final average & 32.8 & 52.5 & 14.7 \\
\hline
\end{tabular}


Table 8: The comparison of the average results of the fuzzy clustering method in the constant amplitude and the constant rate

\begin{tabular}{|c|c|c|c|c|c|}
\hline $\begin{array}{c}\text { Damage } \\
\text { loading type }\end{array}$ & $\begin{array}{c}\text { Loading } \\
\text { frequency } \\
\text { (mm/min) }\end{array}$ & $\begin{array}{c}\text { Amplitude } \\
(\mathrm{mm})\end{array}$ & $\begin{array}{c}\text { Matrix } \\
\text { cracking (\%) }\end{array}$ & $\begin{array}{c}\text { Other } \\
\text { damages } \\
(\%)\end{array}$ & $\begin{array}{c}\text { Fiber } \\
\text { breakage } \\
(\%)\end{array}$ \\
\hline $\begin{array}{c}\text { Constant } \\
\text { amplitude }\end{array}$ & from 25 to 200 & 7.0 & 23.3 & 59.1 & 20.6 \\
\hline Constant rate & 200 & $\begin{array}{c}\text { from 5.5 to } \\
7.0\end{array}$ & 32.8 & 52.5 & 14.7 \\
\hline
\end{tabular}

\subsubsection{The comparison of the results of fuzzy and wavelet clustering methods}

A comparison of the results of the wavelet method and the fuzzy clustering technique is shown in Table 9. As shown in Table 9, it could be concluded that the largest difference between the wavelet method and the fuzzy clustering technique was related to estimate the damage rate of the fiber breakage in the constant frequency fatigue loading. Moreover, the lowest difference was related to determining the percentage of the fiber breakage damage in the constant amplitude fatigue loading. In general, in the constant amplitude fatigue loading, in the wavelet method, with increasing the loading frequency, the percentage of the fiber breakage increased and other damages and matrix cracking decreased. However, in the fuzzy method, the percentage of the fiber breakage decreased and the percentage of matrix cracking and other damages increased. In the constant frequency fatigue loading, in the wavelet transform method, with increasing the loading amplitude, the fiber fracture percentage decreased and the matrix cracking rate and other failures decreased. However, in the fuzzy clustering method, the percentage of matrix cracking was low and the percentage of the fiber breakage and other damages increased. Therefore, the percentage of debonding under both types of fatigue loading and the analysis with both wavelet and fuzzy clustering methods constantly increased. However, the growth of matrix cracking and the fiber breakage in two types of the constant amplitude and the constant frequency in fatigue loads by two methods of wavelet and fuzzy clustering methods act against each other. Such results were also represented in the literature [51], it showed, there was a good concurrence in the results of the wavelet analysis. Both of these techniques were useful tools for monitoring and characterizing the failure modes in composite materials [51]. 
Table 9: The comparison of the average results of fuzzy and wavelet clustering methods in the constant amplitude and the constant rate

\begin{tabular}{|c|c|c|c|c|c|c|c|c|c|c|c|}
\hline \multirow[t]{2}{*}{$\begin{array}{c}\text { Damage loading } \\
\text { type }\end{array}$} & \multirow{2}{*}{$\begin{array}{l}\text { Loading } \\
\text { frequency } \\
(\mathrm{mm} / \mathrm{min})\end{array}$} & \multirow{2}{*}{$\begin{array}{l}\text { Loading } \\
\text { range } \\
(\mathrm{mm})\end{array}$} & \multicolumn{3}{|c|}{$\begin{array}{c}\text { Fiber breakage } \\
\qquad(\%)\end{array}$} & \multicolumn{3}{|c|}{$\begin{array}{c}\text { Other damages } \\
\qquad \%)\end{array}$} & \multicolumn{3}{|c|}{$\begin{array}{l}\text { Matrix cracking } \\
\qquad \%)\end{array}$} \\
\hline & & & 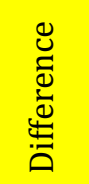 & 胥 & $\begin{array}{l}\frac{ \pm}{0} \\
\sum_{\pi}^{ \pm} \\
3\end{array}$ & 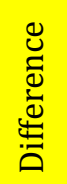 & 胥 & $\begin{array}{l}\frac{\overrightarrow{0}}{0} \\
\stackrel{\vec{\pi}}{3} \\
3\end{array}$ & 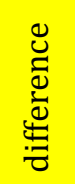 & 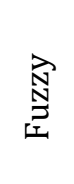 & 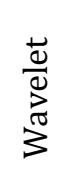 \\
\hline $\begin{array}{l}\text { Constant } \\
\text { amplitude }\end{array}$ & from 25 to 200 & 7.0 & 2.0 & 20.6 & 18.6 & 8.9 & 59.1 & 50.2 & 10.9 & 20.3 & 31.2 \\
\hline Constant rate & 200 & $\begin{array}{c}\text { from } 5.5 \text { to } \\
7.0\end{array}$ & 11.3 & 14.7 & 26 & 7.8 & 52.5 & 44.4 & 3.2 & 32.8 & 29.6 \\
\hline
\end{tabular}

\section{Conclusions}

In this study, by acoustic emission sensors and analyzing experimental data, the damage, including; matrix cracking, the fiber breakage and other damages (debonding, fiber pull-out and delamination) during dynamic loading was investigated. Considering the loading conditions and the results obtained from mechanical tests and the results for the acoustic emission and their comparisons with each other, it can be concluded that for the acoustic emission has been a very practical method for monitoring the condition of composite structures. The analysis of acoustic emission signals was investigated by two wavelet and fuzzy clustering methods. The frequency and the percentage of each damage mode were extracted and expressed separately. Energy and rhythm components were important factors in describing the damage mechanisms of composites and any type of the structure, in general. Therefore, with these components, damages occurring in structures in the service could be well monitored to prevent the damage or increase. The results of this study could be summarized as following;

- The acoustic emission method was a very practical and useful tool for monitoring the health of various polymer-based composite structures.

- The effect of the loading rate for the pure fiber tensile test showed that as the loading rate increased, the maximum force decreased and was inversely related to it. The matrix cracking frequency range was $250-100 \mathrm{kHz}$, the fiber breakage frequency range was $420-500 \mathrm{kHz}$ and the frequency of other damages was $420-250 \mathrm{kHz}$. The results of the effect of the loading frequency on the lifetime indicated that with increasing the frequency, the lifetime decreased and the amount of the maximum stress increased. 
- The results of the effect of the loading range on the lifetime of samples indicated that when the loading frequency was constant and the amplitude increased, the lifetime of the samples decreased and the maximum stress increased. With increasing the number of load cycles and the closer the sample was to its final lifetime, the maximum stress decreased.

- The results of the analysis of the acoustic emission signals for the constant amplitude and the variable frequency fatigue tests illustrated that with increasing the loading frequency, the average percentage of the fiber damage increased, and the matrix cracking decreased and other damages were found.

- A comparison of the results of the wavelet and fuzzy clustering methods demonstrated that the largest difference between these techniques was related to estimate the damage rate of the fiber breakage in the constant frequency fatigue loading. Moreover, the lowest difference was related to determining the percentage of the fiber breakage damage in the constant amplitude fatigue loading. The wavelet closed method was more accurate in determining the percentage of each damage.

In further investigations, the non-destructive tests could be used before fatigue testing to find any initial defects through the manufacturing process. These known initial conditions in the specimen could increase the prediction model in a reliable process.

\section{Appendix}

In this part, the diagram for analyzing acoustic emission data by the wavelet and fuzzy methods is depicted.

\section{Fatigue tests in the constant amplitude}

Sample No. 1
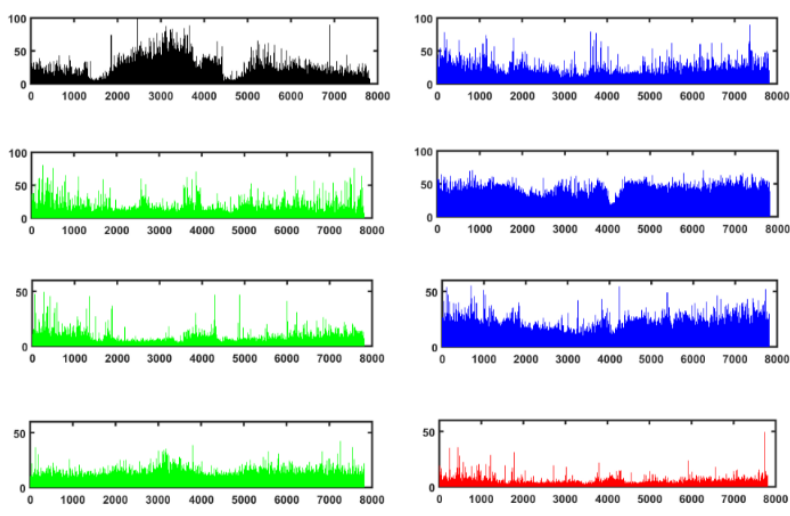

Sample No. 3
Sample No. 2
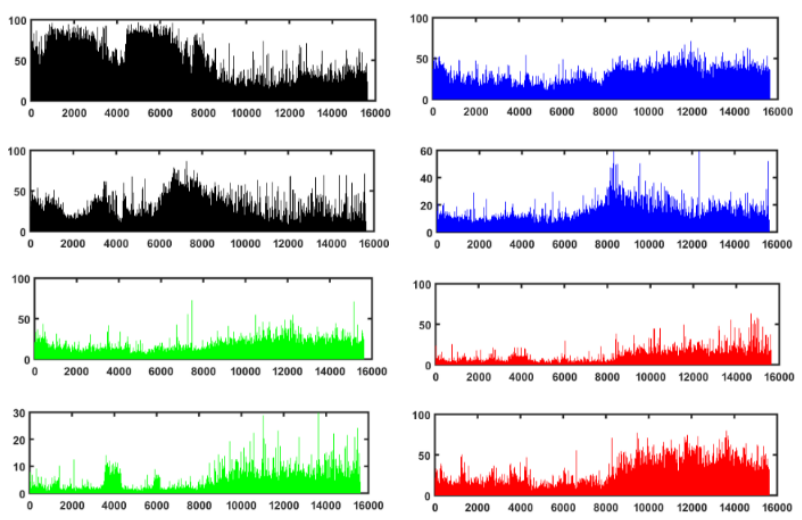

Sample No. 4 

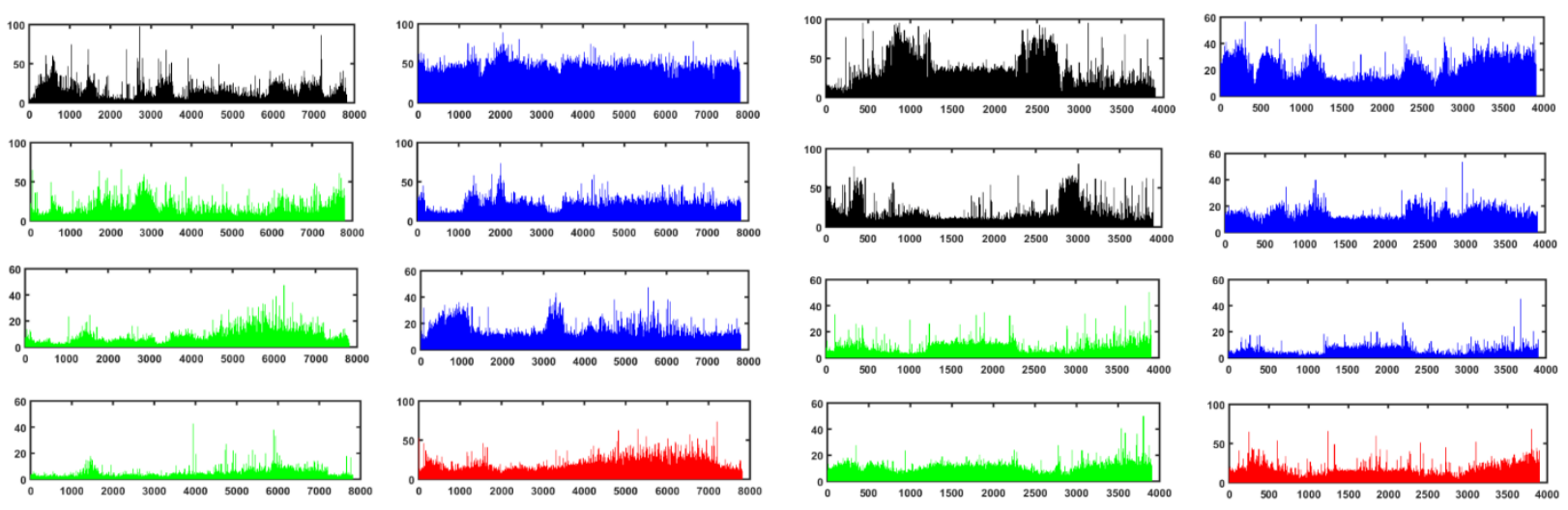

Fatigue tests in the constant rate

Sample No. 4
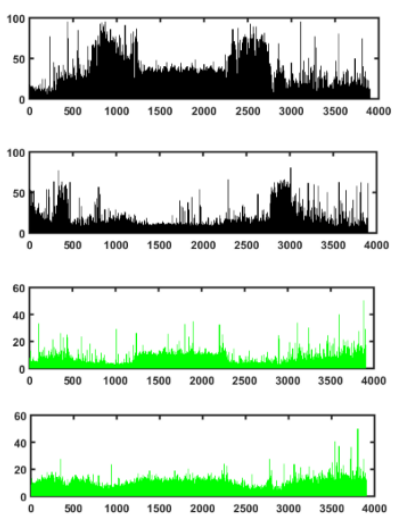

Sample No. 6
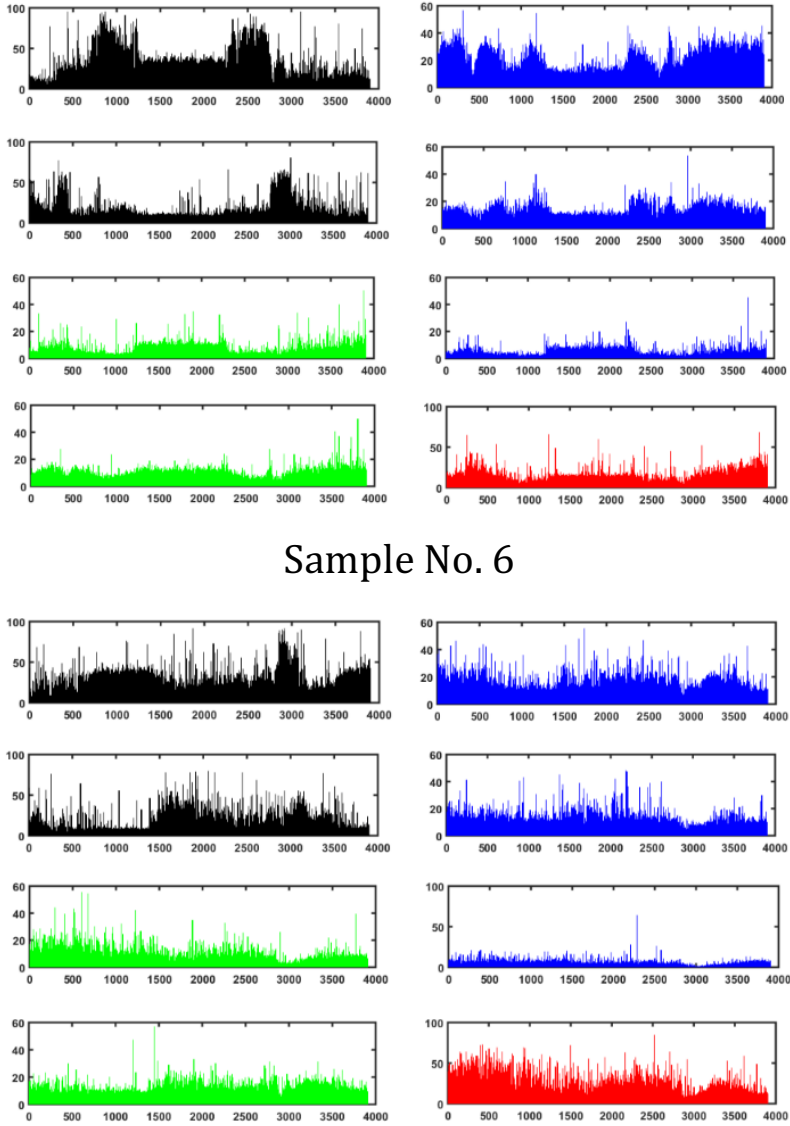

Sample No. 5
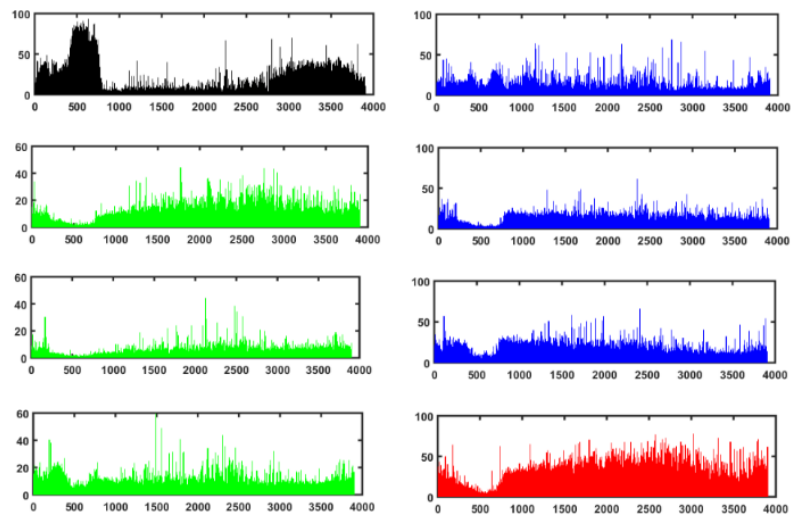

Sample No. 7
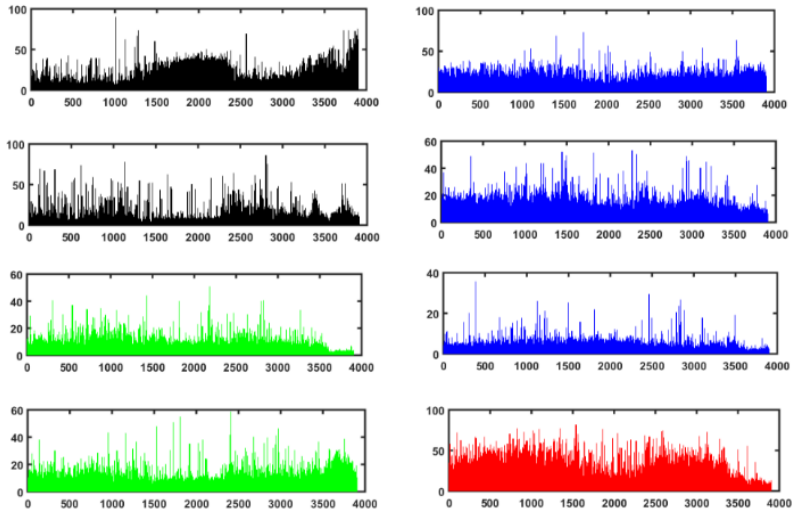

Figure A-1: The energy percentage of each cluster in the wavelet method for all samples (at the mid-life cycle of fatigue testing) 
Fatigue tests in the constant amplitude

Sample No. 1

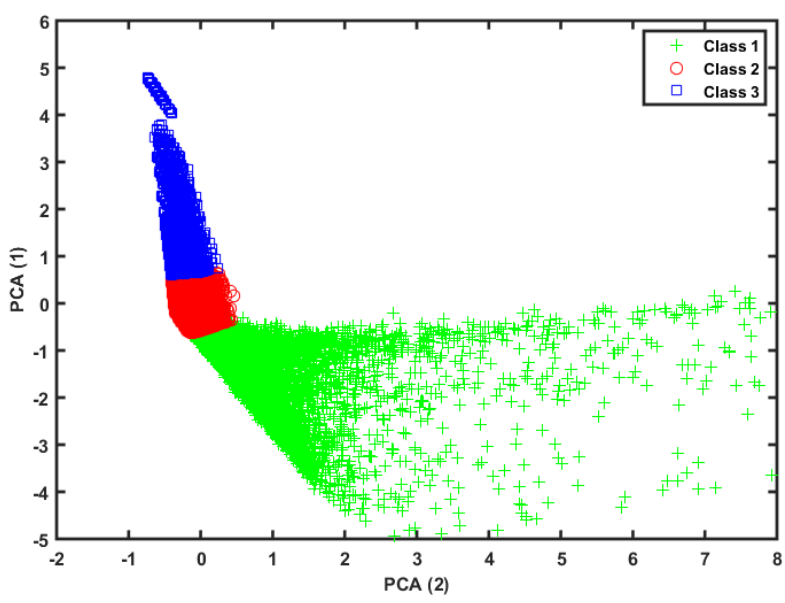

Sample No. 3

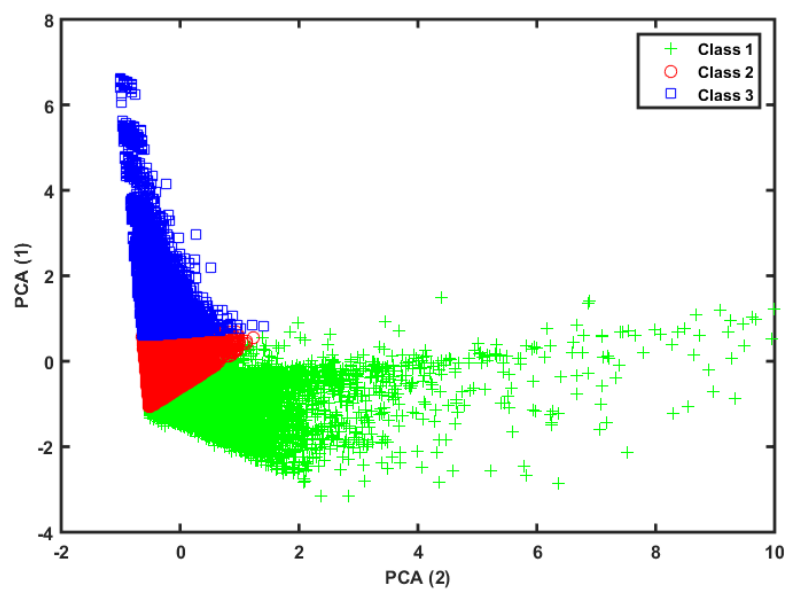

Sample No. 2

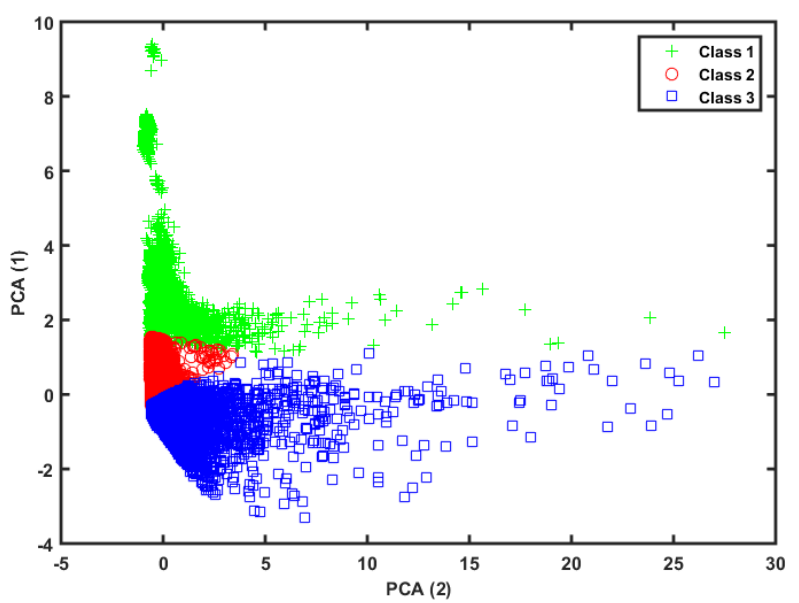

Sample No. 4

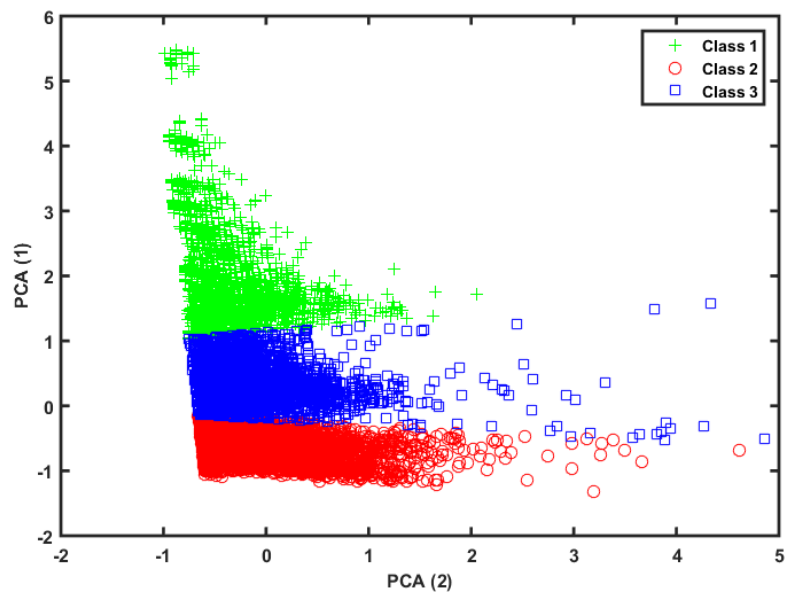

Fatigue tests in the constant rate

Sample No. 4

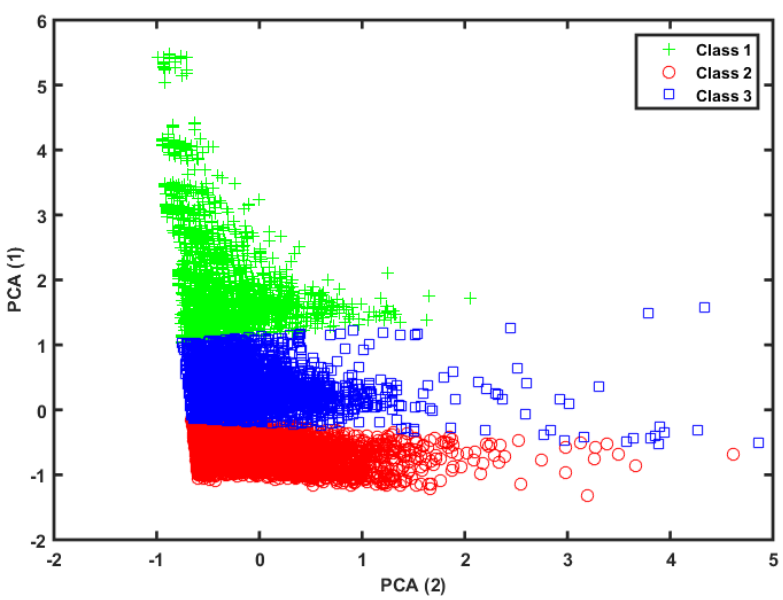

Sample No. 6
Sample No. 5

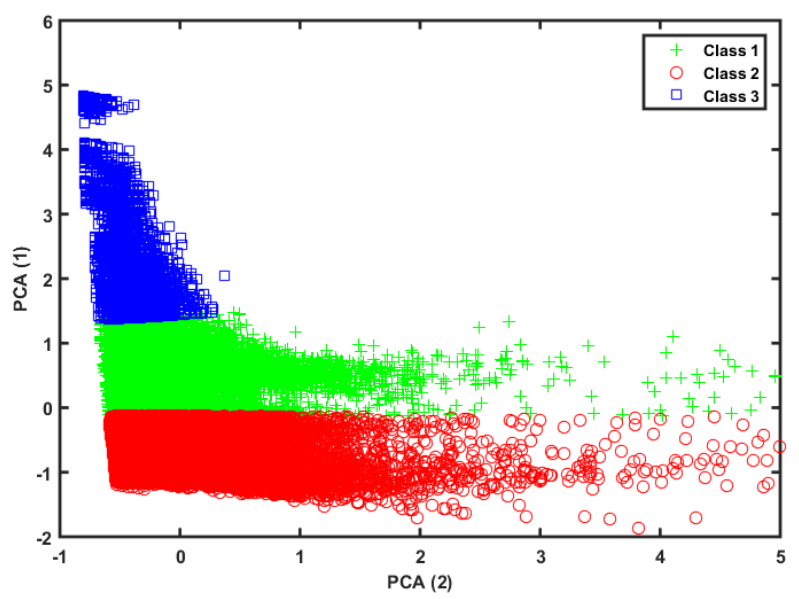

Sample No. 7 

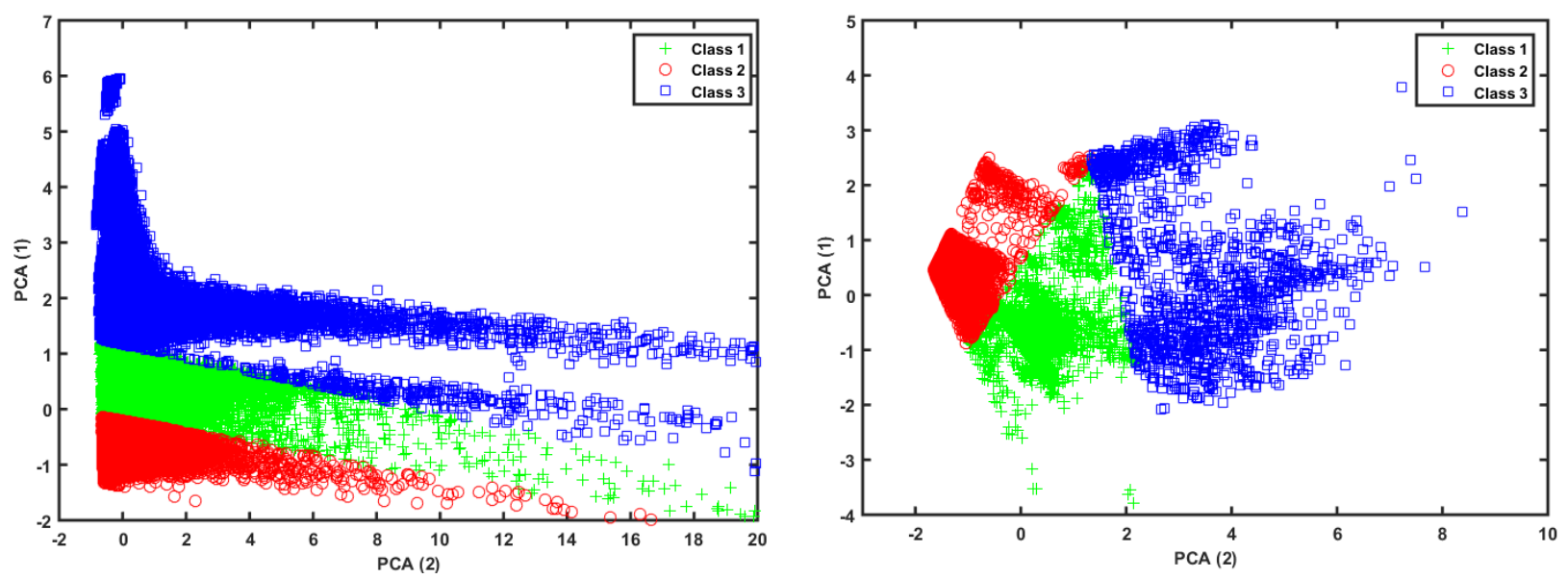

Figure A-2: Clustering of two first-ranked parameters in the fuzzy method for all fatigue samples

\section{Data Availability Statement}

The datasets generated during and/or analyzed during the current study are available from the corresponding author on reasonable request.

\section{References}

[1] Azadi, M., Saeedi, M., Mokhtarishirazabad, M., Lopez-Crespo, P. (2019). Effects of loading rate on crack growth behavior in carbon fiber reinforced polymer composites using digital image correlation technique, Composites Part B: Engineering. 175: 107161. https://doi.org/10.1016/j.compositesb.2019.107161

[2] Ghasemi-Ghalebahman, A., Sayyar, H., Azadi, M., Jafari, S.M. (2018). Failure mechanisms in open-hole laminated composites under tensile loading using acoustic emission, Journal of Science and Technology of Composites. 5(1): 143-152. https://doi.org/10.22068/jstc.2018.30114

[3] Sayar, H., Azadi, M., Alizadeh, M. (2019). Detection of Crack Initiation and Propagation in Aluminum Alloy Under Tensile Loading, Comparing Signals Acquired by Acoustic Emission and Vibration Sensors. Journal of Nondestructive Evaluation. 38, 100. https://doi.org/10.1007/s10921-019-0639-9

[4] Mohammadi Esfarjani, S. (2020). Structural Damage Detection Using Modal Flexibility Method in Honeycomb Composite Sandwich Beam. Romanian Journal of Acoustics and Vibration. 17(1): 51-56.

[5] Saeedifar, M., Zarouchas, D. Damage characterization of laminated composites using acoustic emission: A review, Composites Part B, 195: (2020) 108039, https://doi.org/10.1016/j.compositesb.2020.108039 
[6] Mohammadi Esfarjani, S., Mehdi Salehi, M. (2016). Damage Identification in aluminum T32024 alloy via Cross Correlation Functions. The 15th International Conference of Iranian Aerospace, March 1-3, Tehran, Iran. (In Persian) http://research.iaun.ac.ir/pd/msalehi/pdfs/PaperC_8626.pdf

[7] Mohammadi Esfarjani, S., Mehdi Salehi, M. (2020). Inspection above ground pipeline using vibration responses. Journal of Pipeline System Engineering and Practice. 11(3): 04020021 https://doi.org/10.1061/(ASCE)PS.1949-1204.0000463

[8] Mohammadi Esfarjani, S., Mehdi Salehi, M. (2016). Evaluation of the damage detection capability of inner product vector for LOP and LOSWF defects in V groove weld, Modares Mechanic Engineering, 16(6): 7-16. (In Persian) http://mme.modares.ac.ir/article-15-5470en.pdf

[9] Mohammadi Esfarjani, S. (2020). Evaluation of effect changing temperature on lamb-wave based structural health monitoring, Journal of Mechanical and Energy Engineering (JMEE), 3(4): 329-336. https://doi.org/10.30464/jmee.2019.3.4.329

[10] Mohammadi Esfarjani, S., Mehdi Salehi, M. Ghassemi, A. (2017). Effect of the multiple damages and temperature changes on the natural frequency. Journal of Theoretical and Applied Mechanics. 55(3): 813-822. https://doi.org/10.15632/jtam-pl.55.3.813

[11] De Baere, I., Van Paepegem, W., Hochard, C., Degrieck, J. (2011). On the tension-tension fatigue behaviour of a carbon reinforced thermoplastic part II: evaluation of a dumbbell$\begin{array}{llll}\text { shaped } \quad \text { specimen. } & \text { 30lymer } & \text { 663-672. }\end{array}$ https://doi.org/10.1016/j.polymertesting.2011.05.005

[12] Brunbauer, J., Stadler, H., Pinter, G. (2015). Mechanical properties, fatigue damage and microstructure of carbon/epoxy laminates depending on fiber volume content. International Journal of Fatigue. 70: 85-92. https://doi.org/10.1016/j.ijfatigue.2014.08.007

[13] Azadi, M., Alizadeh, M., Sayar, H. Sensitivity analysis for effects of displacement amplitude and loading frequency on low-cycle fatigue lifetime in carbon/epoxy laminated composites. 12th International Fatigue Congress (FATIGUE 2018). 25 May 2018, Poitiers, France. https://doi.org/10.1051/matecconf/201816522021

[14] Asokan, R., Arumugam, V., Santulli, C., Stanley, A.J. (2012). Acoustic emission monitoring of repaired composite laminates. Journal of Reinforced Plastics and Composites. 31(18): 1226-1235. https://doi.org/10.1177/0731684412455957

[15] Michalcova, L. Kadlec, M. (2015). Crack Growth Monitoring of CFRP Composites Loaded in Different Environmental Conditions Using Acoustic Emission Method. Procedia Engineering. 114: 86-93. https://doi.org/10.1016/j.proeng.2015.08.045 
[16] Aggelis, D.G., Barkoula, N.M., Matikas, T.E., Paipetis, A.S. (2012). Acoustic structural health monitoring of composite materials: Damage identification and evaluation in cross ply laminates using acoustic emission and ultrasonics. Composites Science and Technology. 72(10): 1127-1133. https://doi.org/10.1016/j.compscitech.2011.10.011

[17] Marec, A., Thomas, J-H., El Guerjouma, R. (2008). Damage characterization of polymerbased composite materials: Multivariable analysis and wavelet transform for clustering acoustic emission data. Mechanical Systems and Signal Processing. 22(6): 1441-1464. https://doi.org/10.1016/j.ymssp.2007.11.029

[18] Ni Q.Q., Iwamoto, M. (2002). Wavelet transform of acoustic emission signals in failure of model composites. Engineering Fracture Mechanics. 69(6): 717-728. https://doi.org/10.1016/S0013-7944(01)00105-9

[19] Nikmehr, M., Khamedi, R. (2015). Identification effects of hybrid fibers in composite properties and Acoustic Emission parameters by Fuzzy C- Means. Modares Mechanical Engineering. 15(6): 402-408 (In Persian)

[20] Williams, R.S., Reifsnider, K.L. (1974). Investigation of Acoustic Emission During Fatigue Loading of Composite Specimens. Journal of Composite Materials., 8(4): 340-355. https://doi.org/10.1177/002199837400800403

[21] Loutas, T. H., Kostopoulos, V. (2009). Health monitoring of carbon/carbon, woven reinforced composites. Damage assessment by using advanced signal processing techniques. Part I: Acoustic emission monitoring and damage mechanisms evolution. Composites Science and Technology. 69(2): 265-272. https://doi.org/10.1016/j.compscitech.2008.07.020

[22] Bourchak, M., Farrow, I.R., Bond, I.P., Rowland, C.W., Menan, F. (2007). Acoustic emission energy as a fatigue damage parameter for CFRP composites. International Journal of Fatigue. 29(3): 457-470. https://doi.org/10.1016/j.ijfatigue.2006.05.009

[23] Alizadeh, M., Sayar, H., Azadi, M., Jafari, S.M. (2019). Health Monitoring for Composite under Low-Cycle Cyclic Loading, Considering Effects of Acoustic Emission Sensor Type. Mechanics of Advanced Composite Structures (MACS). 19-26. https://doi.org/10.22075/MACS.2019.16157.1166

[24] Alizadeh, M., Azadi, M., Farrokhabadi, A., Jafari, S.M. (2018). Investigation of displacement amplitude effect on failure mechanisms in open-hole laminated composites under low-cycle fatigue loading using acoustic emission. Modares Mechanical Engineering. 17(12): 435-445 (In Persian) http://mme.modares.ac.ir/article-15-5707-en.html 
[25] ASTM D5766 / D5766M-11 Standard Test Method for Open-Hole Tensile Strength of Polymer Matrix Composite Laminates. Available: https://www.astm.org/Standards/D5766.htm

[26] ASTM E976-10. Standard Guide for Determining the Reproducibility of Acoustic Emission Sensor Response. ASTM International: West Conshohocken; 2010.

[27] ISO 12716, Non-Destructive Testing - Acoustic Emission Inspection - Vocabulary. 1998.

[28] Takahashi, D. (2019). Fast Fourier Transform Algorithms for Parallel Computers, Pages 5-13. Springer. https://doi.org/10.1007/978-981-13-9965-7

[29] Raol., K.R., Kiml., D.N, Hwang., J.J. (2010). Fast Fourier Transform: Algorithms and Applications. Springer. https://doi.org/10.1007/978-1-4020-6629-0

[30] Debnath, L., Ahmad Shah, F. (2015). Wavelet Transforms and Their Applications, Springer. https://doi.org/10.1007/978-0-8176-8418-1

[31] Rao, R.M., Bopardikar, A.S. (1998). Wavelet Transforms: Introduction to Theory and Applications, Addison Wesley Publishing Company, pp. 1-26.

[32] Walnat, D.F. (2002). An Introduction to Wavelet Analysis, Birkhauser Boston, pp. 350. https://doi.org/10.1007/978-1-4612-0001-7

[33] Saeedifar, M., Fotuohi, M., Mohammadi, R., Ahmadi, M., Hajikhani, M. (2014). Classification of damage mechanisms during delamination growth in sandwich composites by acoustic emission, Modares Mechanical Engineering. 14(6): 144-152, 2014. (In Persian) https://mme.modares.ac.ir/browse.php?a_id=4571\&sid=15\&slc_lang=en

[34] Fotuohi, M., Sadeghi, S., Jalalvand, M., Ahmadi, M. (2017). Analysis of the damage mechanisms in mixed-mode delamination of laminated composites using acoustic emission data clustering. Thermoplastic Matrix Composite Materials. 30(3): 318-340. https://doi.org/10.1177/0892705715598362

[35] Miyamoto, S., Ichihashi, H., Honda, K. (2008). Algorithms for Fuzzy Clustering. Springer. https://doi.org/10.1007/978-3-540-78737-2

[36] Toly Chen, T.C., Honda, K. (2020). Fuzzy Collaborative Forecasting and Clustering. Springer. https://doi.org/10.1007/978-3-030-22574-2

[37] Oskouei, A.R., Heydari, H., Ahmadi, M., Farajpur, M. (2012). Unsupervised acoustic emission data clustering for the analysis of damage mechanisms in glass/polyester $\begin{array}{llll}\text { composites. } & \text { Materials } & \text { 47 } & \text { Design. }\end{array}$ https://doi.org/10.1016/j.matdes.2012.01.018

[38] Marec, A., Thomas, J.H., Guerjouma, R.E. (2008). Damage characterization polymer-based composite materials: multivariable analysis and wavelet transform for clustering acoustic 
emission data. Mechanical Systems and Signal Processing. 22(6): 1441-1464. https://doi.org/10.1016/j.ymssp.2007.11.029

[39] Deshpande, A. B. (2006). Characterization of CFRP and GFRP composite materials at high strain rate tensile loading, Thesis. https://soar.wichita.edu/bitstream/handle/10057/553/t06083.pdf?sequence=3 [40] de Groot, P.J., Wijnen, P.A.M., Janssen, R.B.F. (1995). Real-time frequency determination of acoustic emission for different fracture mechanisms in carbon/epoxy composites. Composites Science and Technology. 55(4): 405-412. https://doi.org/10.1016/0266-3538(95)00121-2 [41] Naresh, K., Shankar, K., Rao, B.S., Velmurugan, R. (2016). Effect of high strain rate on glass/carbon/hybrid fiber reinforced epoxy laminated composites. Composites Part B: Engineering, 100: 125-135. https://doi.org/10.1016/j.compositesb.2016.06.007 [42] Naresh, K., Shankar, K., Velmurugan, R. (2018). Reliability analysis of tensile strengths using Weibull distribution in glass/epoxy and carbon/epoxy composites. Composites Part B: Engineering, 133: 129-144. https://doi.org/10.1016/j.compositesb.2017.09.002 [43] Ou, Y., Zhu, D., Zhang, H., Yao, Y., Mobasher, B., Huang, L. (2016). Mechanical properties and failure characteristics of CFRP under intermediate strain rates and varying temperatures.

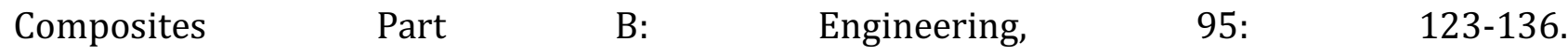
https://doi.org/10.1016/j.compositesb.2016.03.085

[44] Azadi, M., Sayar, H., Ghasemi-Ghalebahman, A., Jafari, S.M. (2018). Tensile loading rate effect on mechanical properties and failure mechanisms in open-hole carbon fiber reinforced polymer composites by acoustic emission approach. Composites Part B: Engineering. 158: 448-458. https://doi.org/10.1016/j.compositesb.2018.09.103

[45] Gilat, A., Goldberg, R.K., Roberts, G.D. (2007). Strain Rate Sensitivity of Epoxy Resin in Tensile and Shear Loading. Journal of Aerospace Engineering. 20(2), 0893-1321. https://doi.org/10.1061/(ASCE)0893-1321(2007)20:2(75)

[46] Yousefi, J., Ahmadi, M., Shahri, M.N., Oskouei, A.R., Moghadas, F.J. (2014). Damage Categorization of Glass/Epoxy Composite Material under Mode II Delamination Using Acoustic Emission Data: A Clustering Approach to Elucidate Wavelet Transformation Analysis. Arabian Journal for Science Engineering. 39: 1325-1335, 2014. https://doi.org/10.1007/s13369-013-0712-0

[47] Fotouhi, M., Ahmadi, M. (2014). Investigation of the mixed-mode delamination in polymer-matrix composites using acoustic emission technique. Journal of Reinforce Plastic Composite. 33(19): 1767-1782. https://doi.org/10.1177/0731684414544391 
[48] Wan, A., Xiong, J., Xu, Y. (2020). Fatigue life prediction of woven composite laminates with initial delamination, Fatigue and Fracture of Engineering Materials and Structures, 2020, 43(9): 2130-2146. https://doi.org/10.1111/ffe.13296

[49] Zhou, W., Zhang, Y-N., Zhao, W-Z. (2020). Evaluation of Progressive Damage and Identification of Failure Mechanisms in Carbon Fiber Woven Composites via Tensile Test. Russian Journal of Nondestructive Testing. 56: 222-233. https://doi.org/10.1134/S1061830920030134

[50] Mohammadi, R., Najfabadi, M.A., Saeedifar, M., Yousefi, J., Minak, G. (2017). Correlation of acoustic emission with finite element predicted damages in open-hole tensile laminated composites. Composites Part B: Engineering, 108: 144-152. https://doi.org/10.1016/j.compositesb.2016.09.101

[51] Fotouhi, M., Heidary, H., Ahmadi, M., Pashmforoush, F. (2012). Characterization of composite materials damage under quasi-static three-point bending test using wavelet and fuzzy C-means clustering. Journal of Composite Materials. 46(15): 1795-1808. https://doi.org/10.1177/0021998311425968

[52] Beheshtizaeh, N., Mostafapour, A. (2017). Processing of acoustic signals via wavelet and Choi-Williams analysis in three-point bending load of carbon/epoxy and glass/epoxy composites. Ultrasonics. 79: 1-8. https://doi.org/10.1016/j.ultras.2017.04.001 